Running head: DIVERSITY CLIMATE SCALE

Perceptions of inequality and intolerance "in the air": Development and initial validation of the Diversity Climate Scale

José A. Soto ${ }^{1}$, Wei Wei ${ }^{1}$, Anna C. Salomaa ${ }^{2}$, Jasmine A. Mena ${ }^{3}$, Natalia Van Doren ${ }^{1}$, and

\author{
Ying Yang 4 \\ ${ }^{1}$ Department of Psychology, The Pennsylvania State University \\ ${ }^{2}$ VA Boston Healthcare System \\ ${ }^{3}$ Department of Psychology, Bucknell University
}

${ }^{4}$ Department of Educational Psychology, Counseling, and Special Education, The Pennsylvania State University

Author Note

José A. Soto (iDttps://orcid.org/0000-0002-7567-2368

Jasmine A. Mena (iD https://orcid.org/0000-0001-7707-7602

Natalia Van Doren https://orcid.org/0000-0001-6044-7208

Note that the current manuscript has not yet been peer-reviewed.

We have no known conflict of interest to disclose. All data and code are available upon request from the authors and will be made publicly available via the Open Science Framework (OSF) repository once ongoing manuscripts using the same data have been published.

Correspondence concerning this article should be addressed to José A. Soto, 310 Moore Bldg., Department of Psychology, The Pennsylvania State University, University Park, PA 16802. E-mail: josesoto@psu.edu 


\begin{abstract}
Diversity climate has been associated with numerous outcomes across psychological, physical, and occupational domains. By diversity climate we refer to individual perceptions of both local and broader societal conditions (implicit and explicit) that reflect receptivity and portrayal of the social groups with which one is affiliated. The Diversity Climate Scale (DCS) was created to measure diversity climate perceptions among individuals with diverse and complex social identities, with a range of importance ascribed to those identities, and across diverse contexts (proximal and distal environments). The DCS was constructed and examined across four separate studies. Study $1(\mathrm{~N}=115)$ presents the development of the scale, preliminary factor structure, and convergent validity. Studies $2(\mathrm{~N}=79)$ and $3(\mathrm{~N}=422)$ confirmed the factor structure of the DCS and established the convergent and discriminant validity with increasingly diverse and nationally representative samples. Study $4(\mathrm{~N}=420)$ extended these analyses with a community sample, examined the predictive validity of the measure, and demonstrated that favorable proximal and distal diversity climate differed significantly across groups with different constellations of marginalized identities and differences in the importance ascribed to those identities. When controlling for lifetime discrimination, perceiving a more positive proximal climate was consistently associated with decreased depressive symptoms and increased life satisfaction, while perceptions of distal climate interacted with proximal climate and discrimination to predict depressive symptoms and life satisfaction. Applications of the DCS and considerations for future research are discussed.
\end{abstract}

Key words: Diversity Climate Scale; Discrimination; Depression; Life satisfaction 


\section{Perceptions of inequality and intolerance "in the air": Development and initial validation of the Diversity Climate Scale}

The chronic, widespread, and worsening maltreatment of marginalized individuals in the U.S. by institutions and their agents (law enforcement, justice system, social services, etc.) is analogous to a pandemic (American Psychological Association [APA], 2020). Inherent in this comparison is the notion that oppressive ideologies spread across individuals and communities and impact how entire groups of people are treated within a society. Technological advances facilitate the capture and immediate dissemination of acts of discrimination, contributing to the increased visibility of the systemic oppression of certain groups within society. This oppression stems from group positionality, which is the relative value/status ascribed to different sociocultural groups (those sharing a social identity such as racial minorities, queer individuals, etc.) within a society. The stark differences in group positionality is a key feature that contributes to acts of discrimination and oppression of marginalized groups and is associated with deleterious health effects (Paradies et al., 2015). This oppression can exert its influence in explicit and implicit ways (Lukachko et al., 2014). Because oppression is not always explicitly observable, it can be said to be "in the air," contributing to toxic diversity climates that impact the health and wellbeing of large segments of a population. Thus, accurately understanding and capturing perceptions of diversity climate (and the subtle and not-subtle slights and insults that contribute to climate) is critical for targeting interventions to promote the success of marginalized groups.

We propose that Diversity climate is one way to conceptualize and understand the impact of systemic inequality on social disparities between marginalized groups and their privileged counterparts. To use race as a prominent example, the health disparities between African 
Americans and European Americans are well-documented, present from early in life, and extend beyond health outcomes into academic and social functioning (Alegria et al. 2010; Chen et al. 2006; CDC report, 2013 Graham, 2011; NCCDPHP, 2004). Racism has been singled out as a possible cause of observed differences in health outcomes (Brondolo et al., 2003; Clark et al., 1999; Williams, 1999). Although compelling, this explanation is incomplete. Even as the number of explicit forms of racism and discrimination in society declined (Cose, 1995; Dovidio, 2001; Pearson et al., 2009), health disparities between African Americans and European Americans persisted, and even increased (Williams \& Jackson, 2005). While a number of structural and institutional barriers (e.g., biased policies and practices, economic disparities that fall largely along racial lines; unequal access to resources) have been advanced to help explain these differences in outcomes, the influence of these barriers on the well-being of marginalized groups is likely to be impacted via individuals' perceptions of whether, how, and why these challenges in one's environment exist to begin with (Bell et al., 2020). For this reason, we contend that the perception of diversity climate-individual perceptions of both local and broader societal conditions with respect to receptivity and portrayal of one's social group(s), including explicit and implicit indicators of such—might be most important to long-term outcomes, rather than direct and explicit experiences of discrimination (Meyer, 2003). In the present paper, we present the development and validation of the Diversity Climate Scale (DCS), a scale that can be used with various marginalized groups and attends to how multiple factors affect the perception of climate.

\section{Understanding the Construct of Diversity Climate}

The term diversity climate is difficult to define because it is and has been used both colloquially and professionally. However, before defining diversity climate, it is helpful to 
consider the term diversity. Others have examined this concept in great detail (see Plaut et al., 2015), but, for our purposes, diversity refers to group identities that are marginalized, underrepresented, or both within the broader society and/or within a local community. Diversity can be represented by an individual, but also by a collection of individuals who share a marginalized identity. Of course, different groups of individuals may define diversity differently (Stevens et al. 2010; Unzueta \& Binning, 2012), thus the experiences of these individuals cannot be equated even if they are part of the same sociocultural group. Importantly, identities intersect because multiple identities are mutually constitutive (Crenshaw, 1989) and can create unique perceptions of diversity climates.

Diversity climate is also used colloquially to refer to how welcoming, supportive and inclusive members of marginalized and underrepresented groups perceive the social and professional atmosphere/environment of an institution (school, workplace, etc.). The climate of an institution can be thought of as a psychologically meaningful representation of the institution's environment (Pargament et al., 1983). It may reflect the observable practices, routines, and behaviors in a setting that perpetuate cultural beliefs and values (Guion, 1973). Thus, diversity climate can refer to an individuals' perception of the value of one's sociocultural group identity in society or the immediate surroundings.

Diversity climate expands on more specific climate constructs such as racial climate. Hurtado and colleagues (2008) define racial climate as the "attitudes, perceptions, behaviors, and expectations around issues of race, ethnicity, and diversity" which are based on lived experiences (p. 205; Hurtado, 1992; Locks et al., 2008). For instance, on a college campus, racial climate is linked with perceived acceptance or rejection of racial diversity at that institution (Chavous, 2005; Reid \& Radhakrishnan, 2003; Solórzano et al., 2000). Of course, attitudes about diversity 
climate are likely to track closely with objective aspects of a setting such as the representation of marginalized groups and the existence of policies and practices that contribute to their success and wellbeing (e.g., Walton \& Cohen , 2007; Lick et al., 2012). However, the broader focus of diversity climate (relative to group-specific climates such as racial climate), stands to offer more information about an environment and would be seen as relevant by multiple constituencies in that environment.

Within industrial-organizational (I/O) psychology (e.g., Kossek \& Zonia, 1993; Mor Barak et al., 1998) researchers have focused on how an employer's visible behaviors and policies reflect an overall diversity climate. These diversity practices are defined as actions (or lack of) by employers that signal an organization's commitment to supporting employees of all backgrounds (Downey et al, 2015; Thomas \& Plaut, 2008). Diversity resistance is a related concept that refers to the behaviors and attitudes expressed or represented by an organization or its individuals that may impede a sense of support and commitment to diversity (e.g., unfair hiring and promotion policies, poor mechanisms for dealing with discrimination in the workplace, poor treatment of minority employees). Thus, diversity resistance is likely linked with a poor diversity climate (McKay et al., 2008).

Other researchers have focused on more explicit measurement of climate perceptions within workplace contexts. For example, Mor Barak and colleagues (1998) measured perceptions of organizational factors (e.g., degree to which management incorporates diverse perspectives) and individual factors (e.g., degree to which employees felt comfortable interacting with diverse others). They found that individuals belonging to historically marginalized and underrepresented groups (i.e., women \& employees of color) were more likely to view the diversity climate as less positive than White men. Climate perception has also been linked to job turnover (McKay et al., 
2008), job satisfaction, and wellbeing among women and racial and ethnic minority employees (Mor Barak et al. 2021).

Belongingness, a concept related to diversity climate, refers to the degree to which members of marginalized groups perceive they are included by a particular community. These climates can range from "chilly" and exclusionary to welcoming and fostering a sense of belonging among marginalized groups (Mauritzi et al., 2013). The literature on belonging, broadly speaking, has long appreciated belongingness as a critical factor in individual wellbeing and thriving (Baumeister \& Leary, 1995; Walton \& Cohen, 2007). In research within academic settings (high schools, colleges), similar constructs have largely echoed these findings (Goodenow, 1993; Hoyle \& Crawford, 1994; Mounts, 2004; Pittman \& Richmond, 2007; Roeser et al., 1996; Tao et al., 2000). Thus, belongingness may, in part, represent the internalized consequences of diversity climate for marginalized individuals. Herein, we define diversity climate as individual perceptions of both local and broader societal conditions that reflect receptivity and portrayal of the social groups with which one affiliates (i.e., one's social identities), and includes explicit and implicit contributors to these perceptions.

\section{Correlates of Diversity Climate}

Diversity climate and related concepts have been linked to wellbeing and social disparities among marginalized groups. For example, campus racial climate is one of the driving factors in lower performance and persistence among students from racial/ethnic minority groups (Hurtado et al., 1998; Reid \& Radhakrishnan, 2003). Simply being a part of a marginalized group on a college campus is correlated with several indicators of adjustment and academic performance (e.g., alienation, underperformance; Nettles et al., 1986; Steele \& Aronson, 1995). These issues are magnified when paired with negative interpersonal experiences of racism or 
discrimination, and can lead to demotivation, disengagement, and dropout if not countered with supportive and positive responses (Cabrera et al., 1999; Hurtado, 1992; Jones, 2002; Nettles \& Perna, 1997; Solórzano \& Bernal,2001). Even if they feel socially accepted, some marginalized students find that their talents and abilities are scrutinized, questioned, and doubted (Davis et al., 2004; Steele, 1997, 2004).

Not surprisingly, marginalized students on campuses perceived to be more hostile tend to experience greater feelings of alienation and lower feelings of attachment (Cabrera \& Nora, 1994; James, 1998). Furthermore, the degree of mismatch between identity and school environment is linked to lower motivation through lower perceptions of school belonging (Byrd \& Chavous, 2011). A sense of belonging has also been linked to academic success among minority students (Walton \& Cohen, 2007) and the transition to college, which often results in attrition of minority students and leads to greater race/ethnicity consciousness-raising experiences (French et al., 2000). Scholars have argued that the higher attrition rate of Black college students (relative to White students) is less a consequence of academic problems than it is psychosocial factors impacting their overall experience and scholarly functioning (Petersen, 2019).

Diversity climate is also important in organizational/work settings. For instance, a report by McKinsey \& colleagues, using data collected from over 1,000 companies across 15 countries, pointed to increased profitability among companies that showed the greatest gains in diversity of their workforce (Dixon-Foyle et al., 2020) versus those with the least diversity gains. Interestingly, McKay and colleagues (2007) found that increased diversity in an organization did not translate to improved diversity climate even within organizations that demonstrated gains in the diversity of their employees. Yet, perceptions of diversity climate were positively related to 
sense of commitment and turnover intentions for White, Hispanic, and especially, Black employees (McKay et al., 2007).

The impact of diversity climate expands to schools, workplaces and surrounding communities. For example, perceptions of LGB (Lesbian, Gay, and Bisexual) climate in schools and communities have been shown to relate to bullying, drug use, depression, suicidal ideation, and truancy in LGB youth (Birkett et al., 2009; Hatzenbuehler, 2011). Perceptions of LGB climate also predicted the wellbeing of the children of LGB parents, regardless of their sexual orientation (Lick et al., 2012). Mere demographic characteristics can also feed into climate perceptions: density of same-sex couples in an area has been identified as a highly consistent predictor of wellbeing, as well as city-level LGB hate crime policies (Lick et al., 2012). These studies highlight the importance of implicit, explicit, interpersonal and systemic contributors to perceptions of climate relative to one's identity group(s).

\section{Expanding the Conceptualization and Measurement of Diversity Climate}

Despite the value in capturing perceptions of diversity climate, a number of conceptual and measurement-related challenges remain. First, most attempts to capture diversity climate rely heavily on direct interpersonal experiences (discrimination, microaggressions, etc.) that inform perceptions of a negative or hostile climate (Reid \& Radhakrishnan, 2003), with a few exceptions (e.g., Kosciw, et al., 2009; Lick et al., 2012). Yet interpersonal bias and maltreatment are neither necessary nor sufficient for individuals to develop a sense of diversity climate. For example, if a person is called an ethnic slur while walking through a college campus, the active support of bystanders or the existence of institutional policies to punish acts of hate may lead that person's to have a more favorable diversity climate perception than if the event occurred with no supportive responses. Thus, a more comprehensive measure of diversity climate should 
incorporate aspects that relate to direct experiences of maltreatment as well as those that reflect indirect messages and indicators of how marginalized individuals are regarded in those spaces.

A second challenge is the need to differentiate between diversity climate and belonging. For instance, while feeling like one belongs is a common struggle for members of marginalized communities, individuals may or may not see their marginalized identity as a reason for their exclusion. One example of this entanglement is highlighted in Goodenow's (1993) measure of university belonging. The scale itself includes items such as "other students like me the way I am," which fails to dissociate perceptions of belonging as being tied to identity-specific factors (race, sexual orientation, etc.) from non-identity factors such as personality traits or perceived ability. Of course, certain traits have been linked to certain identities via stereotypes (Steele, 1999; Steele \& Aaronson, 1995). As a result, measuring belongingness and not diversity climate limits our ability to understand if individuals are linking their perceptions of exclusion to their group identity. Thus, even though theory and empirical data suggest that they are associated (i.e., more positive diversity climates relate to a greater sense of belonging; Johnson et al. 2007), separating perceptions of diversity climate specifically associated with one's identity is a more nuanced approach which is essential to improving the diversity climate in specific environments. A third issue is the inability to distinguish between the different levels of climate that exist within an individual's context (different departments within an organization or university; campus vs surrounding town; city/state of residence vs country as a whole). For example, someone may be part of a politically progressive educational institution located in a much more politically conservative geographical area and thus may feel relatively unsafe the minute they are outside of the campus setting. Similarly, an individual who resides in a relatively diversityfriendly environment may still experience great distress as they witness the rampant incidences 
of abuse and maltreatment that others from the same group suffer in other places. This may be difficult to disentangle but the concept of multiple levels of oppression discussed in Author and Author (2011) and Author et al. (2012) can provide an analogous frame for thinking about diversity climate. They posit that individuals can experience oppression at various levels: distal, proximal, and personal. Distal oppression captures the experiences tied to simply belonging to a marginalized group that enjoys relatively less status and privilege within society (high distal oppression). Proximal oppression refers to contextual factors in the local environment that can affect how oppression is experienced. Finally, personal oppression refers to how one's status is conceptualized or experienced at an individual level (e.g., oppressed minority ideology; Sellers et al. 1998). This conceptualization is consistent with the minority stress model which describes proximal and distal stress processes that combine to produce mental health outcomes (Meyer, 2003). Thus, the extent to which individuals experience these different levels of oppression likely shapes their perceptions of diversity climate. The ability of a measure to distinguish how individuals perceive their more immediate surroundings versus how they might perceive their broader context (within this city, within this country, etc.) would capture a more nuanced sense of climate that might be uniquely predictive of different outcomes (Author \& Author, 2011; Author et al., 2012).

The idea of multiple levels of oppression also parallels the distinction advanced by others in the field between understanding how oppression is embedded in the institutional, societal, and cultural fabric of our nation (i.e., structural racism) versus simply examining individual prejudice or discrimination (Neblett, 2019; Salter \& Adams, 2013; Salter et al., 2018; Williams et al., 2019). These approaches all highlight the need to focus on systemic change and the need for psychological researchers to adopt a broader perspective than has been the case, historically. 
These structural manifestations of oppression, however, are not always perceived by the targeted individuals (Williams et al., 2019). Presumably, awareness of these structural forces of oppression might lead marginalized individuals to feel greater distress about their struggles and the plight of their fellow group members. Conversely, a failure to appreciate these systemic influences may provide some benefit to the individual insofar as they may be ignorant of the extent and magnitude of inequality or bias in society. Assessing diversity climate in a manner that would capture perceptions of oppression at different levels (distal vs. proximal) would allow us to understand how structural racism might be manifested at the individual psychological level, which is important in its own right.

Fourth, marginalization and oppression are not limited to racial and ethnic minorities but are experienced by several groups whose identities are not fully accepted and/or are not accorded fair treatment (e.g., LGB community, Muslims, women, and more). Accordingly, others have attempted to create climate measures for specific groups such as Oswald and colleagues' (2010) scale for assessing LGB community climate. While the members of each of these groups face struggles specific to their identities, there may also be important commonalities in their experiences and in the structure of oppression that causes bias, discrimination, and violence towards these groups. Differentiating these similarities and differences with a single diversity climate scale is both practically and academically useful. For example, it would also be useful to understand whether diversity climates that make individuals of a particular social identity feel more oppressed also impact individuals with other marginalized social identities in the same way. To study this, at present, requires multiple climate measures to accurately represent the climate with respect to various marginalized identities. A measure that captures a sense of diversity climate as it pertains to multiple identities promises to deliver greater flexibility and 
utility. Such a scale would also allow a cohesive literature on the construct of diversity climate to grow in a linear fashion.

Fifth, membership in a social identity group is not commensurate with the importance of that identity to a given person. Thus, since no group is monolithic, it plausible that individual differences associated with the level of importance that an individual places on one or more of their identities are linked to perceptions of oppression (Begeny \& Huo, 2017). Although we know that there are differences in identity development that predict numerous outcomes (Phinney, 1996; Sellers et al. 1998), climate assessment has largely taken a 'one-size-fits-all' approach to social identities where being a member of a group is tantamount to seeing that identity as important to them and anyone who uses the same identification. The importance an individual places on a given identity (similar to Sellers' racial salience concept; Sellers et al., 1997) can shape perceptions of diversity climate and this subtlety has received almost no attention in the literature.

Finally, the complex realities of social identities are such that we each hold multiple identities (cisgender woman, lesbian, Black, etc.) that can be mutually constitutive and yield a unique intersectional identity (Crenshaw, 1989; Shields, 2008). Researchers interested in diversity climate (and in general climate) have often overlooked the fact that considering the combined effect of social identities can lead an individual to experience an environment in different ways than when examining any of these in isolation (Crenshaw, 1989). Measurement should consider this when asking people to report on their perceptions of their environment, as it may be difficult or impossible to tease apart the different effects of each identity on perceptions of climate (see Bowleg, 2008). Framing questions in ways that do not force people to parse out these aspects of their identity may be difficult but doing so effectively can lead to much richer 
and more accurate data. Such data can guide interventions, policies, as well as future research and can serve as a means to measure progress toward an equitable society. Therefore, integrating an intersectional perspective within the assessment of diversity climate represents an important step forward (Torres et al., 2018).

\section{The Current Study}

In recognition of the importance of the construct of diversity climate to the success and wellbeing of many in our society across multiple domains (e.g., school, work settings) and the need to improve the measurement of this construct, the current study presents the development of the Diversity Climate Scale. The scale was created to capture individual perceptions about proximal and distal environmental climate with respect to implicit and explicit messages that signal representation, acceptance, and inclusion (or lack thereof) of those the social identity(ies) one deems most important to oneself (Meyer, 2003; Author \& Author, 2011; Author et al., 2012)). We were guided by the challenges delineated above to create a scale that (a) taps into the subtle or implicit messages about group positionality, as well as explicit ones, present in one's environment that contribute to diversity climate; (b) can differentiate between various levels of one's environment that may have distinctly separate diversity climates; (c) is compatible with the experiences of multiple marginalized groups; and (d) allows for the assessment of diversity climates as perceived by individuals with unique intersectional identities as indicated by them, rather than the researcher.

Our overall approach included establishing the initial factor structure of the scale with a sample of ethnic minority college students, and then expanding to national samples that included greater diversity (e.g., gender identity, sexual identity, religion), to establish convergent and divergent validity. We also examined how diversity climate differed depending on the specific 
identities measured, as well as the intersection of those identities and how climate related to key markers of wellbeing and ill-being, independently and in conjunction with one another and with experiences of discrimination.

\section{Study 1: Establishment of the Diversity Climate Scale}

The goal of study 1 was to establish the Diversity Climate Scale by administering an initial pool of items to a diverse sample of college students. Our goal was to explore the structure of the Diversity Climate Scale and reduce the initial item pool to the final scale items. We also assessed the convergent validity of the scale by administering the Racial Climate Scale (Reid \& Radhakrishnan, 2003). We expected a moderate correlation between diversity climate and racial climate given that the latter represents a similar construct, although more narrowly focused to one marginalized identity (race), within a particular environment (academic institution).

\section{Methods}

\section{Transparency and Openness}

Across all of four studies we indicate how we arrived at our sample sizes, relying on established conventions for exploratory and confirmatory factor analyses. Exploratory analyses were subjected to a post-hoc power analyses using G-Power version 3.1.9.7 (Erdfelder et al., 2005) when appropriate. Data exclusions, all manipulations, and all measures used across the studies are reported in the manuscript or in supplementary materials. All data and code are available upon request from the authors and will be made publicly available via the Open Science Framework (OSF) repository once ongoing manuscripts using the same data have been published. Data were analyzed using IBM SPSS Statistics version 27 (IBM Corp., 2020), PROCESS Macro 3.5 (Hayes, 2021), and MPlus version 8 (Muthén \& Muthén, 2017). The study designs and analyses were not preregistered. 


\section{Participants}

Participants were 115 college students attending a university in the northeastern U.S. All participants self-identified as ethnic/racial minorities. Thirty-seven percent of the participants were African American or Black, 22.6\% Hispanic, 37.4\% Asian, and 2.6\% other ethnic/racial groups (e.g., Pacific Islander, American Indian \& Middle Eastern). Seventeen percent of the participants were international students. The majority $(60.9 \%)$ of the participants were female. Age information was not collected, although the majority (85\%) of participants were first- and second-year college students.

Our target sample size for study 1 was 100 participants given recommendations that this sample size is the minimum to achieve acceptable power in an exploratory factor analysis, and possibly good power if the factor structure is clear (Comrey \& Lee, 1992; Kyriazos 2018). In total we recruited 252 participants total over the course of two semesters, but for the purpose of the diversity climate scale we were only interested in examining the responses of those who identified as racial or ethnic minorities $(n=115)$, as the scale items were specifically designed to be completed by members of marginalized groups.

\section{Measures and Procedure}

Data were collected via an online survey delivered through the Qualtrics platform. After reading the study consent form, participants indicated their consent by clicking next. Participants completed several demographic questions (e.g., gender, nationality, ethnicity/race), the questionnaires noted below, and some additional measures not used here (see supplemental materials for a complete list of measures administered). All procedures and measures included in all the studies described below were approved by the university's institutional review board. Students received course credit for participating in studies 1, 2 and 3. 
Diversity Climate Scale (DCS). The DCS first provided an explanation that people can have multiple group identities (e.g., gender, race/ethnicity, sexual orientation) and that these may vary in importance to their sense of self. Participants were then asked to select which of these categories they deemed as most important (no limit to number of identities selected) and that they should keep these in mind when answering the subsequent diversity climate items. Once their set of identities was selected, participants were presented with 54 items intended to capture different aspects of diversity climate. The initial set of items was generated by the authors after consulting existing scales that measure similar constructs with the express intent of representing a range of climate experiences (explicit and implicit) of varied marginalized group members, referencing different settings (i.e., immediate environment as well as in their broader community and society), and including both positive and negative events/messages associated with climate (e.g., "The institutions of US society function in ways that hurt the members of my group," "Outside of my immediate group of friends, there are people who look like me in my community). Participants rated each item on the extent to which they agreed or disagreed with the phenomenon described in the item ( 1 = "Strongly Agree" to 5 = "Strongly Disagree") with higher mean scores reflecting a more positive diversity climate.

General Campus Climate and Racial Experiences. Reid and Radhakrishnan's (2003) measure of (1) general campus climate experienced by students within a university and (2) climate as it specifically pertains to race were used in Study 1 . The racial climate scale consists of two subscales, the racial experiences scale and university perceptions. The former assesses the types of racial interactions experienced by participants at their university, while the latter focuses on perceptions about how the university approaches issues pertaining to race. Only the racial experiences subscale of the racial climate scale was available for this study (i.e., items from the 
university perceptions subscale were not collected). The Racial Experiences subscale consists of five items that assess the extent to which students had experienced or witnessed examples of discrimination or poor treatment on their campus (e.g., "I have experienced racial insensitivity from other students"). The General Campus Climate subscale consisted of 4 items that assess perceptions of general campus diversity climate (e.g., "I feel left out of things here at the university”). Items for both scales were rated on a 5-point scale ranging from 1 (strong agreement) to 5 (strong disagreement). Thus, high mean scores on the scale indicate a better general campus climate as well as more positive racial experiences. The Racial Experiences subscale and General Campus Climate subscale demonstrated good reliability in our sample $(\alpha=$ .88 and .80 , respectively).

\section{Results and Discussion}

We conducted an exploratory factor analyses (EFA) with principal axis factoring and Promax rotation using SPSS to examine underlying factors. Examination of the resultant scree plot, eigenvalues, and the factor-to-factor differences in eigenvalues, suggested that the scale represented three reliable factors. Next, we examined individual item loadings from the EFA. We used the more conservative cut-off point of 0.70 for items to count as significantly loading on a factor (Bandalos \& Finney, 2010) and removed loadings below 0.70. Although this cut-off is more conservative than most suggest, we were primarily interested in retaining items that were strong reflections of the constructs represented by each factor and we were also interested in substantially reducing the total number of items (Bandalos \& Finney, 2010). This resulted in the elimination of 40 items from our pool and three factors total (two with six items each and one with two items). 
After examining the items in each factor (Table 1), we noticed that the two items in factor 3 were negatively worded relative to the rest of the scale. That is, factor 3 items were written such that greater endorsement equated to more positive climate perceptions and, as such, would need to be reverse coded to be on the same scale as the rest of the scale items. . These results align with several studies that have shown that when scales are factor analyzed, an extra factor often emerges that is unique to the negatively worded items (DiStefano \& Motl, 2006; Schweizer \& Rauch, 2008; Spector et al., 1997). While historically, the inclusion of both positively and negatively worded items in survey scales has often been suggested as a way of reducing acquiescence bias (Likert, 1932; Cronbach, 1950), more recent work using classical test theory (CTT), confirmatory factor analysis (CFA), and item response theory (IRT) suggests that these items generally do not function equivalently to positively worded items (Barnette, 2000; Sliter \& Zickar, 2014; Weems \& Onwuegbuzie, 2001; Zeng et al., 2020). Thus, we opted to remove these items from our scale. Moreover, two items are too few to form a reliable scale. Therefore, we decided to remove factor 3 resulting in the final Diversity Climate Scale consisting of two factors with 6 items each.

Table 1

The Diversity Climate Scale and Factor Loadings of EFA in Study 1.

\begin{tabular}{llll}
\hline \multicolumn{1}{c}{ Items } & \multicolumn{3}{c}{ Factor loadings } \\
\cline { 2 - 4 } & $\begin{array}{c}\text { Factor 1 } \\
\text { (Distal } \\
\text { Climate) }\end{array}$ & $\begin{array}{c}\text { Factor 2 } \\
\text { (Proximal } \\
\text { Climate) }\end{array}$ & $\begin{array}{c}\text { Factor 3 } \\
\text { (Dropped) }\end{array}$ \\
\hline $\begin{array}{l}\text { Much of the news or publicity regarding members of my } \\
\text { group is negative and damaging. }\end{array}$ & 0.90 \\
$\begin{array}{l}\text { People of my group(s) are more closely scrutinized than } \\
\text { people of other groups. }\end{array}$ & 0.90 \\
$\begin{array}{l}\text { The institutions of US society function in ways that hurt } \\
\text { the members of my group. }\end{array}$ & 0.81 \\
$\begin{array}{l}\text { The structure of US society makes it difficult for } \\
\text { members of my group to truly thrive. }\end{array}$ & 0.80 &
\end{tabular}


Members of my group have many worries and concerns those members of other groups do not have to confront.

This country has failed to incorporate individuals of my group in a meaningful manner.

My peers treat me with less respect because of my group membership(s).

I feel invisible to the people around me because of my group membership.

I feel isolated in my everyday environment because of my identity.

People make me feel like an outsider because of the group(s) I belong to.

When I am outside of my immediate community, I am concerned for my safety because of my identity.

I worry that my comments are not taken seriously because of my unique identity.

I feel represented by people like me in my local community.

Outside of my immediate group of friends, there are people who look like me in my community.

0.71

We next examined the contents of items in each factor and observed that factor 1 mainly described broader social attitudes/practices pertaining to one's marginalized identities, while factor 2 described interpersonal experiences and sentiments characterizing one's more immediate environment. Thus, factor 1 was labeled the distal climate subscale and factor 2 was labeled the proximal climate subscale. The final scale items and factor loadings of each item are presented in Table 1. The reliability (Cronbach's alpha) of the distal climate and proximal climate subscales were 0.93 and 0.90 , respectively, reflecting good to excellent internal consistency. The correlation between the two subscales was $0.49(p<.001$; Table 2).

We also explored the relationship between the two climate-related subscales from Reid and Radhakrishnan (2003) - the General Campus Climate Scale and the Racial Experiences Subscale of the Racial Climate Scale — and our two Diversity Climate Scale subscales. The 
results suggest that the distal climate and proximal climate subscale were moderately associated with the Racial Experience Subscale and the General Campus Climate subscale (Table 2).

In sum, the EFA reduced the initial poll of items from 54 to a 12 -item measure that represented two distinct factors capturing perceptions about more distal (society at large) or proximal (immediate environment) climates. The subscales showed moderate relationships with an existing general campus climate scale and a subscale from a racial climate scale that measured a similar construct in a university setting. Therefore, study 1 provided preliminary evidence for the structure of the Diversity Climate Scale as well as initial convergent validity. To fully establish the structure and validity of the DCS we sought to confirm the scale factor structure using a second sample and further examine convergent and discriminant validity of the scale. Table 2

Study 1 correlations $(N=114)$ between the Diversity Climate scale and the Climate scale from Reid and Radhakrishnan (2003)

\begin{tabular}{lcccc}
\hline \multicolumn{1}{c}{ Variables } & 1 & 2 & 3 & 4 \\
\hline 1. Distal Climate & -- & & & \\
2. Proximal Climate & $.49^{* *}$ & -- & & \\
3. Racial Experiences & $.35^{* *}$ & $.47^{* *}$ & -- & -- \\
4. General Campus Climate & $.36^{* *}$ & $.49^{* *}$ & $.19^{*}$ & \\
$\quad M(S D)$ & $3.01(1.04)$ & $3.59(0.92)$ & $3.21(0.77)$ & $3.70(0.98)$ \\
\hline Note. $^{* *} p<.01 ; * p<.05$. & & & &
\end{tabular}

\section{Study 2: Confirming Factor Structure and Establishing Scale Validity}

The goal of study 2 was to confirm the factor structure of the DCS by administering it to a separate sample of diverse college students. In addition to confirming the factor structure of the scale, study 2 also further explored the convergent and discriminant validity of the DCS. The 
survey we used for Study 1 was therefore expanded to include a set of scales that assessed constructs theoretically related to diversity climate (e.g., discrimination) and theoretically unrelated constructs (e.g., emotion regulation and parenting). We expected the DCS to be moderately correlated with the discrimination scale and weakly to not at all correlated to the emotion regulation and parenting measures.

\section{Methods}

\section{Participants}

Participants were 79 college students attending a university in northeastern U.S. participated in the study. All participants self-identified as ethnic/racial minorities. The majority (76.8\%) of the participants were female. Average age of the participants were 19.27 years old $($ range $=18-27)$. Twenty-five percent of the participants were African American or Black, 35.4\% Hispanic, 35.4\% Asian, and 4.2\% other ethnic/racial groups (e.g., Pacific Islander, American Indian, and Middle Eastern). In total we recruited 248 participants, but as was the case for study 1, we were only interested in examining the responses of those who identified as racial or ethnic minorities) for confirming the factor structure of the diversity climate scale.

According to the general rules-of-thumb developed by Bentler \& Chou (1987) and Nunnally (1967), which specified a minimum of 5 observations/participants per estimated parameter for adequate power, the study was adequately powered to conduct the CFA analyses. Furthermore, others have argued that the target sample size should be 20 participants per factor (Arrindel \& van der Ende, 1985), which also suggests adequate sample size given the results of study 1 which identified two reliable and interpretable factors, though the number of participants was sufficient even for a scale with a three-factor structure.

\section{Measures and Procedure}


The procedure for study 2 was similar to study 1 . In addition to completing the DCS, demographics, and questionnaires listed below, there were additional measures completed that are not used here (see supplemental materials for a complete list of measures administered in Study 2).

Discrimination. Discrimination was assessed with the Daily Discrimination subscale of the Perceived Discrimination Scale (Williams et al., 1997). This 9-item subscale assesses chronic, routine, and less overt experiences of discrimination that have occurred to the person based on their group membership (e.g., race, ethnicity, gender, etc.). Participants were asked to indicate how often they have experienced the behavior described in each statement because of their race/ethnicity (e.g., "You are treated with less courtesy than other people are"). The items are measured on a 4-point Likert scale, with end points of 1 (Often) and 4 (Never). Items were recoded and averaged to form score to represent participants daily discrimination experience with a higher score indicating more frequent encounters of discrimination $(M=1.99, S D=.72)$. The scale demonstrated good reliability in the current sample $(\alpha=.91)$.

Emotion Regulation. Emotion Regulation Questionnaire (ERQ; Gross \& John, 2003) was used to assess participants' use of emotion regulation strategies. The cognitive reappraisal subscale consisted of 6 items (e.g., "When I want to feel more positive emotion, I change the way I'm thinking about the situation."); the expressive suppression subscale consisted of 4 items (“I control my emotions by not expressing them."). Items were rated on a 7-point, Likert-type scale $(1=$ strongly disagree; $7=$ strongly agree $)$. Subscale scores were computed as the average of its respective items. The Cognitive Reappraisal Scale $(M=4.73, S D=1.06)$ and Suppression subscale $(M=3.64, S D=1.20)$ showed acceptable internal reliability $(\alpha=.85 ; \alpha=.75)$. 
Helicopter Parenting. Helicopter parenting (i.e., parents being overprotective and overly attentive toward their children) was measured with the Helicopter Parenting scale (Schiffrin et al., 2014). The helicopter parenting subscale (9 items; e.g., "My parents had/will have a say in what major I chose/will choose.”) and autonomy support subscale (6 items; e.g., My parents encourage me to discuss any academic problems I am having with my professor.) were included in the current study. Items were rated on a 6-point Likert scale with $1=$ strongly disagree and $6=$ strongly agree. Subscale scores were computed as the average of its respective items and a higher score indicated a higher level of respective subscale construct. The helicopter parenting subscale $(M=2.75, S D=0.77)$ and autonomy support subscale $(M=4.17, S D=0.86)$ showed acceptable internal reliability $(\alpha=.72 ; \alpha=.75)$.

\section{Results and Discussion}

A confirmatory factor analyses (CFA) was conducted in MPlus 8.3. The two-factor structure model representing the distal climate and proximal climate subscales is presented in Figure 1 . Three widely used indices of practical fit were utilized to evaluate the goodness of fit of the model: CFI (Bentler, 1990), RMSEA (Browne \& Cudeck, 1993; Steiger \& Lind, 1980), and TLI (Tucker \& Lewis, 1973). The cutoffs for good fit recommended by researchers for the three indices are higher than 0.95 for CFI (Hu \& Bentler, 1999), beyond 0.95 for TLI (Hu \& Bentler, 1999) and lower than 0.05 for RMSEA (Browne \& Cudeck, 1993). Based on the overall pattern of these practical indices, the fit of the two-factor model was good: $\mathrm{CFI}=.954, \mathrm{TLI}=$ .951, RMSEA $=.058$. Factor loadings were all above 0.6 (see Figure 1). The relationship between the two subscales was $0.50(p<.001)$. Therefore, the subscales and items determined from Study 1 remained psychometrically valid and confirmed that the DCS had an identifiable and stable factor structure. 


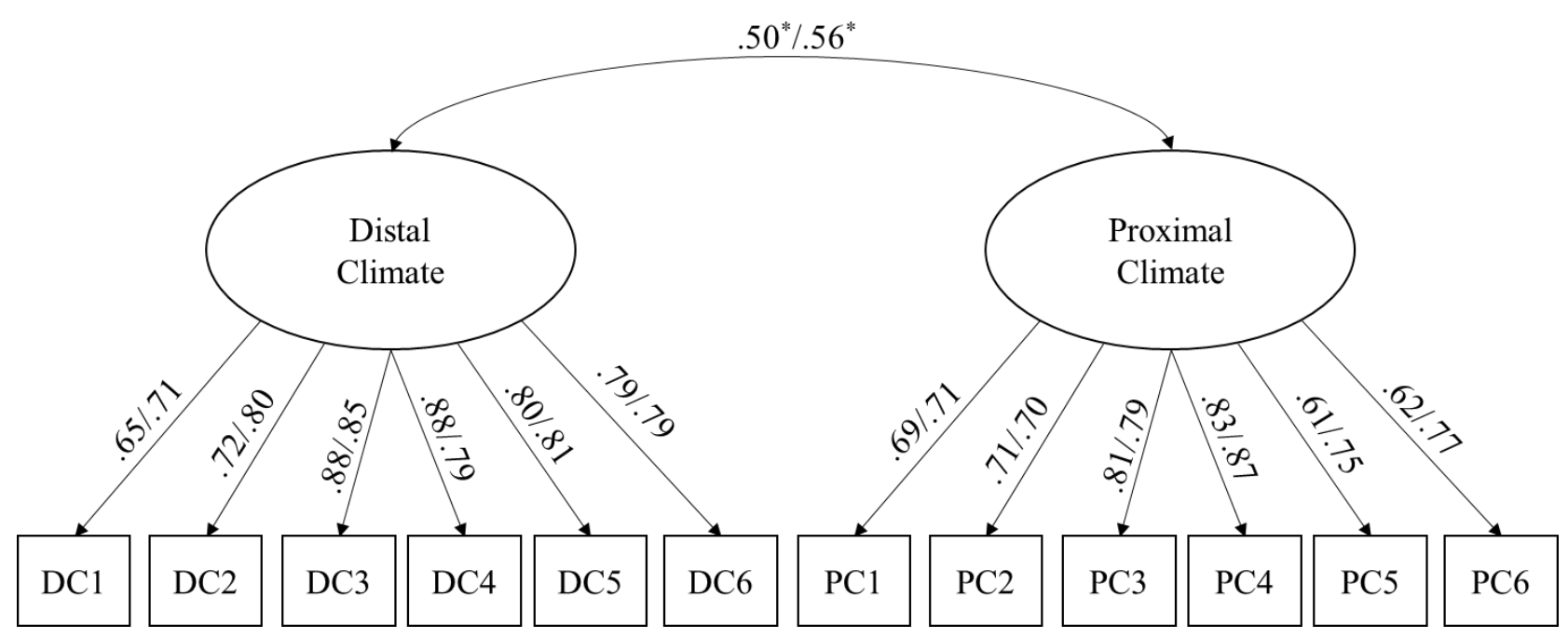

Figure 1. Study 2 and study 3 confirmatory factor analysis with primary factor loadings. DC $=$ Distal Climate. $\mathrm{PC}=$ Proximal Climate. Numbers before slash represent results from study 2 and numbers after slash represent results from study 3 .

*indicates that the correlation between two subscales was significant, $p<.01$.

\section{Convergent Validity}

We examined the extent to which the diversity climate subscales related to the measure of everyday discrimination. Both the distal and proximal climate subscales were negatively related to daily discrimination at a moderate level (Table 3). Consistent with our hypotheses, more frequent encounters of discrimination were associated with lower levels of perceived diversity climate.

\section{Discriminant Validity}

Next, we examined the correlations between the diversity climate subscales and the emotion regulation subscales as well as the helicopter parenting scale. As expected, the distal and proximal climate subscales were not significantly related to emotion regulation subscales (either cognitive reappraisal or suppression; see Table 3). Similarly, the diversity climate subscales were not related to helicopter parenting and autonomy. 
The results of study 2 provided preliminary support for the structure of the DCS in a separate sample of ethnic minority college students. The pattern of correlations between the DCS subscales and additional measures also provided evidence of convergent and discriminant validity. While encouraging, the sample for these analyses was limited in a couple of ways. First, the sample size was acceptable, but low. According to the general rules-of-thumb (Bentler \& Chou, 1987; Nunnally, 1967), we had enough participants to conduct the CFA analyses, but a larger sample would provide greater confidence. Second, the participants in study 2 were limited to students at the same university as those in study 1 . Therefore, expanding the sample to a larger and more representative sample would further establish the robustness of the DCS.

\section{Table 3}

Study 2 correlations $(N=79)$ between the diversity climate scale and other measures.

\begin{tabular}{|c|c|c|c|c|c|c|c|c|}
\hline & & 1 & 2 & 3 & 4 & 5 & 6 & 7 \\
\hline 1. & Distal Climate & -- & & & & & & \\
\hline 2 . & Proximal Climate & $.71^{* *}$ & -- & & & & & \\
\hline 3. & Discrimination & $-.53^{* *}$ & $-.53^{* *}$ & -- & & & & \\
\hline 4. & Cognitive Reappraisal & -.12 & .12 & -.10 & -- & & & \\
\hline 5. & Suppression & .05 & -.10 & $.24^{*}$ & -.01 & -- & & \\
\hline 6 . & Helicopter Parenting & -.07 & -.10 & .20 & .12 & -.05 & -- & \\
\hline \multirow{2}{*}{\multicolumn{2}{|c|}{ 7. Autonomy Support }} & .03 & .10 & -.03 & $.33^{* *}$ & .11 & .05 & -- \\
\hline & & $\begin{array}{c}2.78 \\
(1.07)\end{array}$ & $\begin{array}{c}3.59 \\
(0.89)\end{array}$ & $\begin{array}{c}1.99 \\
(0.72)\end{array}$ & $\begin{array}{c}4.73 \\
(1.06)\end{array}$ & $\begin{array}{c}3.64 \\
(1.20)\end{array}$ & $\begin{array}{c}2.74 \\
(0.77)\end{array}$ & $\begin{array}{c}4.17 \\
(0.86)\end{array}$ \\
\hline
\end{tabular}

Note. ${ }^{* *} p<0.01 .{ }^{*} p<0.05$. 


\section{Study 3: Confirmation of Factor Analysis and Scale Validity}

The goal of study 3 was to confirm the factor structure of the DCS by administering the scale to a large, nationally representative student sample. To do so, we made use of a data set collected via Prolific $($ C that included a large number of students from across the United States that identified as either Black or Latinx. These data were part of a separate data collection project examining emotion regulation in response to discrimination. As with study 2 , we also sought to further explore the convergent and discriminant validity of the scale with theoretically related constructs (e.g., racial climate) and unrelated constructs (emotion regulation).

\section{Methods}

\section{Participants}

Participants in the study were 422 students enrolled in post-secondary education across U.S. About half (53.2\%) of the participants were pursuing a bachelor's degree, $4.5 \%$ pursuing trade/technical/vocational training, $13.7 \%$ pursuing an associate degree, $17.5 \%$ pursuing a master's degree, $3.8 \%$ professional degree, and $7.3 \%$ doctoral degree when the data were collected. Average age of participants were 23.83 years old $(S D=5.69$, range $=18-53)$. All participants self-identified as African American (47.6\%) or Latinx (52.4\%). About half of the participants were female (51.6\%). As per the power considerations specified in study 2 for a confirmatory factor analysis, the sample size was well powered.

\section{Measures and Procedure}

Participants were recruited for an experimental online study on emotion regulation in the context of experiencing discrimination. Therefore, participants were randomized to different conditions as part of the study. Participants completed an online vignette study where they were asked to imagine having received discriminatory/rude feedback from a professor and then were 
asked to engage in a writing task afterward meant to engage them in either cognitive reappraisal or rumination of the imagined incident. Afterward, the participants completed the DCS, demographics, as well as several other measures. Only the measures relevant to the DCS validity analyses are reported here, but all measures are provided in the supplemental materials.

Racial Climate Scale. The Racial Experiences subscale and University Perceptions subscale from Reid \& Radhakrishnan's Racial Climate Scale (2003) was used in the current study to assess convergent validity. Higher scores on both of the Racial Climate scales indicate better racial climate. The Racial Experiences subscale $(M=3.54, S D=1.03)$ and University Perceptions subscale $(M=3.57 ; S D=.91$ demonstrated good reliability in the current sample $(\alpha$ $=.86 ; \alpha=.82$, respectively).

Emotion Regulation. As with Study 3, emotion regulation was assessed with the Emotion Regulation Questionnaire (ERQ; Gross \& John, 2003). The Cognitive Reappraisal subscale $(M=4.85, S D=1.24)$ and Suppression subscale $(M=4.16, S D=1.43)$ showed good reliability $(\alpha=.88 ; \alpha=.80)$ in the current sample.

\section{Results and Discussion}

\section{Confirmatory Factor Analysis}

A CFA was conducted in MPlus 8.3 to assess how well the data fit our previous twofactor model of the DCS. As was the case with study 2, the two-factor structure fit the data well: $\mathrm{CFI}=.940, \mathrm{TLI}=.926, \mathrm{RMSEA}=.062$. Factor loadings were all above $0.70($ See Figure 1$)$. The relationship between the distal and proximal climate subscales was $0.56(p<.001)$. Therefore, the subscales and items determined from Study 1 remained psychometrically valid in the larger student sample and suggest that the DCS has an identifiable and stable factor structure. Because the data for this study included a discrimination manipulation that could conceivably impact 
responses on the DCS (completed after the condition manipulation), we ran the CFA analyses separately by condition and the findings were consistent across both conditions, with the model indicating good fit in both cases and each sub-sample containing sufficient cases for adequate power (see supplementary materials for more detailed information).

\section{Convergent and Discriminant Validity}

The diversity climate subscales both positively related to the racial experience's subscale of the racial climate scale at a moderate level (Table 4). However, the diversity climate subscales were not related to the university perceptions scale. Although this was unexpected, it is possible that the university perceptions scale may be too narrow to be overlap conceptually with the distal climate scale and may be broader than the immediate environment students are referencing when completing the proximal climate scale (e.g., they may be thinking about contexts such as their dorms or classes and may differentiate these from the university as a whole). As expected, and consistent with the results from study 2 , the diversity climate subscales were not related to emotion regulation subscales (i.e., cognitive reappraisal and suppression).

Table 4

Study 3 correlations $(N=422)$ between the Diversity Climate scale and other measures.

\begin{tabular}{lcccccc}
\hline & 1 & 2 & 3 & 4 & 5 & 6 \\
\hline 1. Distal Climate & -- & & & & \\
2. Proximal Climate & $.57^{* *}$ & -- & & & \\
3. Racial Experience & $.25^{* *}$ & $.35^{* *}$ & -- & & \\
4. University Perception & -.02 & .02 & $.17^{* *}$ & -- & \\
& & & & & \\
5. Cognitive Reappraisal & -.02 & .03 & .01 & .06 & --
\end{tabular}




$\begin{array}{lccccccc}\text { 6. Suppression } & & .04 & -.03 & .18^{* *} & .01 & -.01 & -- \\ & & & & & & & \\ & M(S D) & 2.28 & 3.32 & 3.54 & 3.57 & 4.85 & 4.16 \\ & (1.03) & (1.04) & (1.03) & (0.91) & (1.26) & (1.43)\end{array}$

Note. ${ }^{* *} p<0.01$.

\section{Limitations}

The consistency across the first three studies provided favorable evidence for the structural and conceptual soundness of the DCS. However, the samples for studies 1-3 consisted exclusively of racial and ethnic minorities and were limited to post-secondary students. One of our explicit goals in creating the scale was to assess diversity climate perceptions among marginalized groups, broadly speaking, and not just among ethnic and racial minority students. Therefore, our next step was to demonstrate that the DCS could be reliably used with a community-based adult sample that is more representative in terms of intersecting identities.

\section{Study 4. Confirming Factor Structure and Predictive Validity in a Community Sample}

The primary objective of study 4 was to confirm the two-factor structure of the DCS with a broader, community-based sample that included individuals from a diverse set of marginalized groups (i.e., gender minorities, sexual minorities, and racial and ethnic minorities and their various intersections). If the scale could demonstrate good psychometric properties with members of diverse marginalized groups, then the results would support its use with a broad range of marginalized groups, including but not limited racial/ethnic minority groups and make an important contribution to the diversity climate literature. Another goal of Study 4 was to compare the different marginalized groups comprising our sample on the diversity climate subscales to explore whether differences were present based on the different identities endorsed by our participants and the valence associated with those identities. Finally, although Study 2 
demonstrated moderate correlations between both climate subscales and everyday discrimination, we were not able to parse out relative contributions of each of these constructs to health outcomes as these were not included in Study 2. Thus, we were also interested in examining whether the DCS subscales would relate to indicators of mental health and wellbeing above and beyond the variance accounted for by lifetime experiences of discrimination.

\section{Methods}

\section{Participants}

Participants were 420 individuals identified as either ethnic/racial, gender, or sexual minorities (or who did not identify with any of these minority statuses) recruited via Qualtrics Panels. The mean age of participants was 41.8 years $(S D=18.92)$. Among those identifying with a marginalized group ( $85.7 \%$ of the overall sample), 197 participants indicated that they were a racial-ethnic minority, 127 indicated a gender minority status (self-identified as non-binary gender or transgender), and 219 indicated a sexual minority status. The ethnic-racial makeup of the participants was: $60.2 \%$ White, $19.5 \%$ black, $6.9 \%$ Latino, 5.5\% American Indian or Alaska Native, $14.3 \%$ Asian, $0.5 \%$ Native Hawaiian, $1 \%$ Middle Eastern and 3.3\% other races. Around $40 \%$ of the overall sample was female, $29 \%$ was male, and $26.9 \%$ identified as non-binary.

As was the case, with study 3 , the power considerations regarding the sample needed for a confirmatory factor analysis indicated that, as a whole, the sample was well powered. However, interest in examining the factor structure for separate marginalized groups necessitated conducting the CFA analyses with smaller subsamples. In these instances, the lowest subsample size was 127 , which is still above the minimum suggested for sufficient power as discussed above given the number of participants relative to the number of cases to factors and free parameters (Arrindel \& van der Ende, 1985; Bentler \& Chou; 1987; Kyriazos, 2018). Additional 
analyses undertaken on the sample were subjected to power analyses and these are reported after each relevant set of analyses.

\section{Measures and Procedure}

The procedures were similar to the procedures used in studies 1-3 in that participants completed the DCS, demographics, and additional measures (see supplemental materials for the complete list of measures included). In this case, two of the additional measures captured mental health and wellbeing as well as discrimination experiences. These were used to establish predictive validity and incremental validity, respectively. Participants were compensated according to Qualtrics Panels policies.

The Center for Epidemiologic Studies Depression Scale (CES-D). The CESD (Radloff, 1977) was utilized to assess participants' level of depressive symptomatology within the past seven days. The scale consists of 20 statements (e.g., "I was bothered by things that usually don't bother me") rated on a 4-point Likert scale with end points of 0 (rarely or none of the time - less than 1 day) and 3 (mostly or almost all the time -5 to 7 days). Higher values indicate a greater frequency of depressive symptoms. Positively worded items were reverse coded, and all items were summed into a total score to represent the participants' overall depression score $(M=19.31, S D=10.08)$. The scale had good reliability in this sample $(\alpha=.89)$

Satisfaction with Life Scale (SWLS). Participants' life satisfaction was assessed with the Satisfaction with Life Scale (Diener et al., 1985). The SWLS consists of five statements (e.g., “In most ways my life is close to my ideal.") asking participants about perceptions of their satisfaction with their life as a whole using a 7-point Likert scale $(1=$ strongly disagree to $7=$ strongly disagree). The scale demonstrated good reliability $(\alpha=.91)$. All items were averaged 
into a mean score to represent the participants' overall life satisfaction score with higher scores representing higher life satisfaction $(M=4.20, S D=1.37)$.

Discrimination. Discrimination was assessed with the Lifetime Discrimination subscale of the Perceived Discrimination Scale (Williams et al., 1997). This 11-item subscale assesses major incidents of discrimination experienced by an individual. Participants were asked to indicate how many times they have experienced the events described in each statement because of their group membership (e.g., "you were fired," "you were hassled by the police") using a 6point Likert scale, with end points of 1 (almost every day) and 6 (never). Lifetime discrimination scores were created by summing the number of events that happened at least once to each participant.

\section{Results and Discussion}

\section{Confirmatory Factor Analysis}

We first conducted a CFA with the entire sample to confirm that the two-factor structure was valid among a community sample made up of diverse marginalized individuals. The result showed that the two-factor structure fit the sample well: $\mathrm{CFI}=.931, \mathrm{TLI}=.914, \mathrm{RMSEA}=.061$. We also separately examined whether the scale structure was valid for each of the largest marginalized groups in the sample (i.e., racial/ethnic minorities, gender minorities, and sexual minorities) with a series of CFAs given our explicit interest in using the scale with diverse groups. The results of the CFAs suggested that the two-factor structure of the DCS was stable and valid across different marginalized groups with overall good fit indices (racial/ethnic minorities $[n=197]$ : CFI $=0.91, \mathrm{TLI}=0.90, \mathrm{RMSEA}=0.10$; gender minorities $[n=127], \mathrm{CFI}=$ 0.93, TLI $=0.91$, RMSEA $=0.09$; and sexual minorities $[n=219], \mathrm{CFI}=0.95, \mathrm{TLI}=0.93$, 
RMSEA $=0.07$ ) and acceptable factor loadings (see supplemental Table 1 for more detailed information).

\section{Diversity Climate Across Different Marginalized Groups}

We next conducted a series of ANOVAs to examine the mean diversity climate scores across the different identity groups in our sample. To do so, we first divided the sample into six groups based on the various social identities claimed by each participant on their demographics survey: those with no marginalized identities, those identifying only as racial/ethnic minorities, those identifying only as sexual minorities, those identifying as sexual and gender minorities, those identifying as sexual and racial minorities, and those identifying as sexual, gender and racial minorities. There were two intersectional identity combinations (e.g., racial and gender minority, and only gender minority) that were too small $(n<4)$ to include in further analyses, as power was limited to make meaningful comparisons across these groups.

The results of the ANOVA analyses revealed significant differences across the different groups on the distal and proximal climate subscales, $F(5,410)=27.02, p<.001 ; F(5,410)=$ 24.72, $p<.001$, respectively. G-Power calculations for these analyses given a small to medium (.18) effect size indicated good power (.82). An examination of the means in Table 5 shows that the control group (no marginalized identities endorsed) perceived the most positive distal climate, while those endorsing an intersectional identity including sexual and gender minorities perceived the least positive distal climate. The group that endorsed an intersectional identity including sexual, gender, and racial minority also reported low distal climate scores which was significantly lower than the control group, the racial minority only group, and the sexual minority only group. A similar pattern was observed for the proximal climate scale, with the control group once again demonstrating the most positive proximal climate and sexual, gender, 
and racial minorities reporting the least positive proximal climate. The sexual and gender minority group also had lower proximal climate scores than all other groups except for those identifying as sexual, gender, and racial minorities. These results suggest that individuals having multiple minority statuses may experience less positive diversity climates, with the combination of sexual and gender minority status being associated with particularly low climate scores.

Table 5

Mean differences in the diversity climate scale across different marginalize groups in study 4.

\begin{tabular}{|c|c|c|c|}
\hline & & Distal Climate & Proximal Climate \\
\hline Groups & $N$ & $M(S D)$ & $M(S D)$ \\
\hline Control Group & 61 & $3.39^{\mathrm{a}}(1.06)$ & $3.83^{\mathrm{a}}(1.04)$ \\
\hline $\begin{array}{l}\text { Ethnic-Racial } \\
\text { Minority }\end{array}$ & 136 & $2.65^{\mathrm{b}}(0.99)$ & $3.42^{\mathrm{a}}(0.96)$ \\
\hline Sexual Minority & 71 & $2.78^{b}(0.98)$ & $3.56^{\mathrm{a}}(0.92)$ \\
\hline $\begin{array}{l}\text { Sexual and Gender } \\
\text { Minority }\end{array}$ & 89 & $1.71^{\mathrm{c}}(0.77)$ & $2.41^{\mathrm{b}}(1.04)$ \\
\hline $\begin{array}{l}\text { Sexual and Racial } \\
\text { Minority }\end{array}$ & 25 & $2.27^{\mathrm{bc}}(1.14)$ & $3.29^{\mathrm{a}}(1.08)$ \\
\hline $\begin{array}{l}\text { Sexual, Gender, } \\
\text { and Racial Minority }\end{array}$ & 34 & $1.94^{\mathrm{c}}(0.96)$ & $2.32^{b}(1.13)$ \\
\hline Total & 416 & $2.5(1.1)$ & $3.19(1.14)$ \\
\hline
\end{tabular}

\section{Predictive and Incremental Validity}

Two hierarchical multiple regressions were conducted with only those individuals who identified as belonging to one or more marginalized groups (i.e., excluding the control group; $\mathrm{n}=$ 
359) to examine the predictive validity of proximal and distal climate on depressive symptoms and life satisfaction while accounting for lifetime discrimination. Lifetime discrimination was entered in step 1 and the DCS subscales in step 2. Two and three-way interactions were entered in steps 3 and 4, respectively, and significant results were probed using SPSS Process Macro. Results of these regressions are presented in Table 6.

Table 6

Results of hierarchical multiple regressions (final step) predicting mental health and wellbeing from the diversity climate subscales and discrimination in study 4.

\begin{tabular}{|c|c|c|c|c|c|c|}
\hline \multirow{2}{*}{ Predictor } & \multicolumn{3}{|c|}{ Depressive Symptoms } & \multicolumn{3}{|c|}{ Life Satisfaction } \\
\hline & $\operatorname{Beta}(\mathrm{SE})$ & $t$ & $p$ & $\operatorname{Beta}(\mathrm{SE})$ & $t$ & $p$ \\
\hline Lifetime Discrimination (LD) & $0.21(0.06)$ & 3.71 & 0.00 & $-0.02(0.14)$ & -0.15 & 0.88 \\
\hline Distal Climate (DC) & $-0.02(0.06)$ & -0.36 & 0.72 & $0.13(0.13)$ & 0.96 & 0.34 \\
\hline Proximal Climate (PC) & $-0.18(0.05)$ & -3.58 & 0.00 & $0.21(0.12)$ & 1.71 & 0.09 \\
\hline DCxLD & $0.30(0.07)$ & 4.09 & 0.00 & $-0.57(0.17)$ & -3.31 & 0.00 \\
\hline PCxLD & $0.11(0.06)$ & 1.95 & 0.05 & $-0.02(0.14)$ & -0.12 & 0.91 \\
\hline $\mathrm{DCxPC}$ & $0.19(0.03)$ & 5.39 & 0.00 & $-0.26(0.08)$ & -3.12 & 0.00 \\
\hline DCxPCxLD & $0.18(0.04)$ & 4.26 & 0.00 & $-0.38(0.10)$ & -3.76 & 0.00 \\
\hline
\end{tabular}

Lifetime discrimination (step 1) and proximal climate (step 2) significantly predicted depressive symptoms. None of the variables in steps 1 and 2 significantly predicted life satisfaction. Two-way interactions (distal climate $\mathrm{x}$ discrimination, distal climate $\mathrm{x}$ proximal climate) significantly predicted depressive symptoms and lifetime satisfaction, which were further qualified by a three-way interaction between discrimination and both climate scales for depressive symptoms (final model, $R^{2}=.34, F[7,351]=25.92, p<.001 ; R^{2} \Delta=.03, p<.001$ ) and life satisfaction (final model, $R^{2}=.17, F[7,351]=9.95, p<.001 ; R^{2} \Delta=.03, p<.001$ ). As 
depicted in Figure 2, for those with more positive proximal climates (top panel) who also had a more positive view of the distal climate, discrimination was associated with increased depressive symptoms (Figure 2) and decreased life satisfaction (Figure 3). This relationship was the inverse for those who perceived an unfavorable distal climate. As proximal climate became more negative (middle and lower panels), this pattern went away.

While identifying with specific marginalized identities was clearly related to perceiving different distal and proximal climates, it is also possible that diversity climate perceptions could differ based on whether these self-identifications were also seen as important by a participant (asked at the introduction of the DCS). To test this notion, we compared mean diversity climate scale scores between participants who claimed a specific minority status(es) and also selected the same minority status(es) as important to their identity (concordant group) to those who claimed a minority status(es) but did not ascribe importance to same identities (discordant group). We were only able to test this among the three marginalized groups (racial minorities, sexual minorities, and sexual and gender minorities) with the largest subsamples and with a roughly balanced number of concordant and discordant individuals.

Figure 2

Three-way interaction between DCS subscales and discrimination in predicting depression scores 


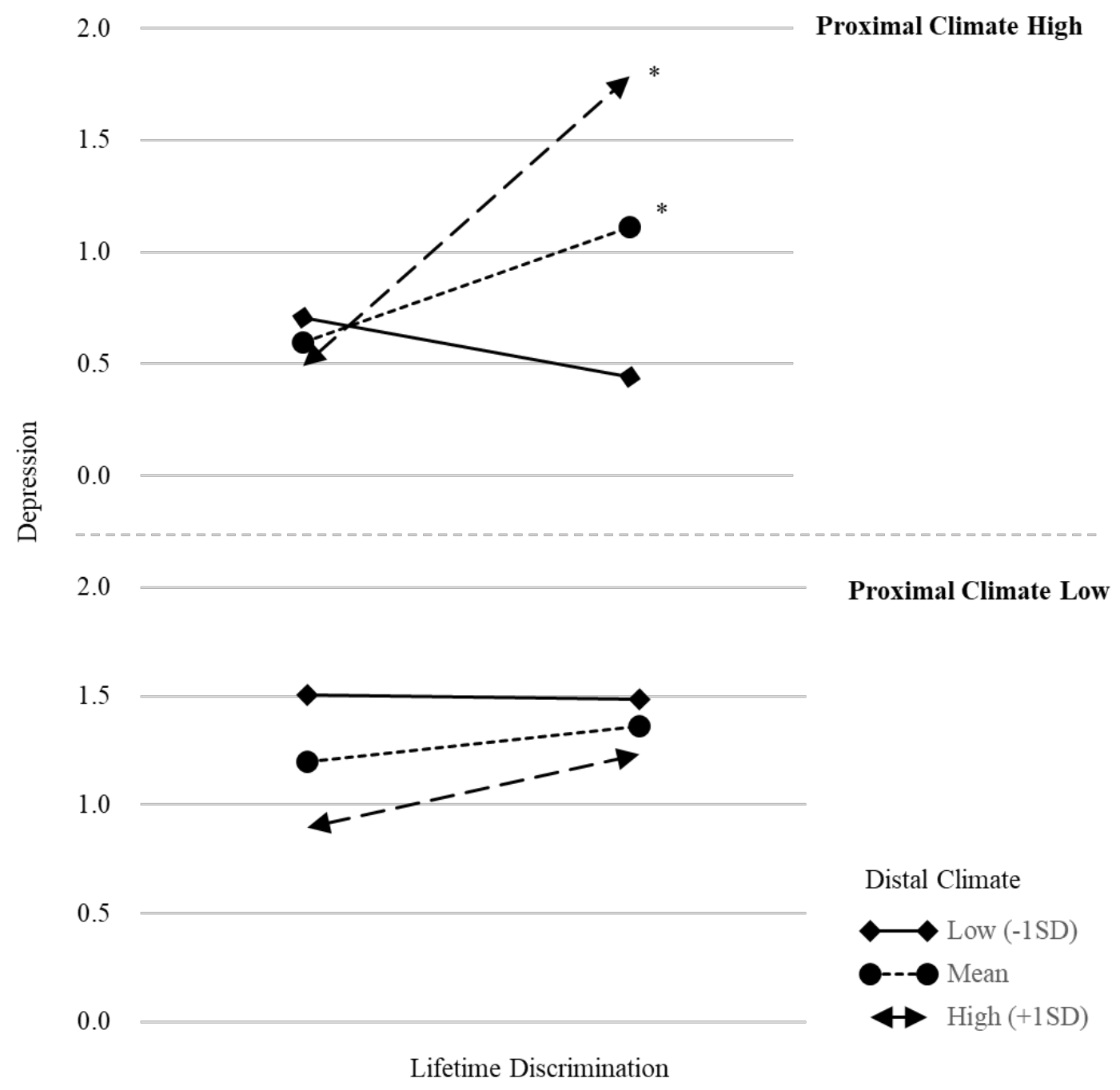

*Indicates significant simple slopes $(p<.05)$ 
Figure 3

Three-way interaction between DCS subscales and discrimination in predicting life satisfaction
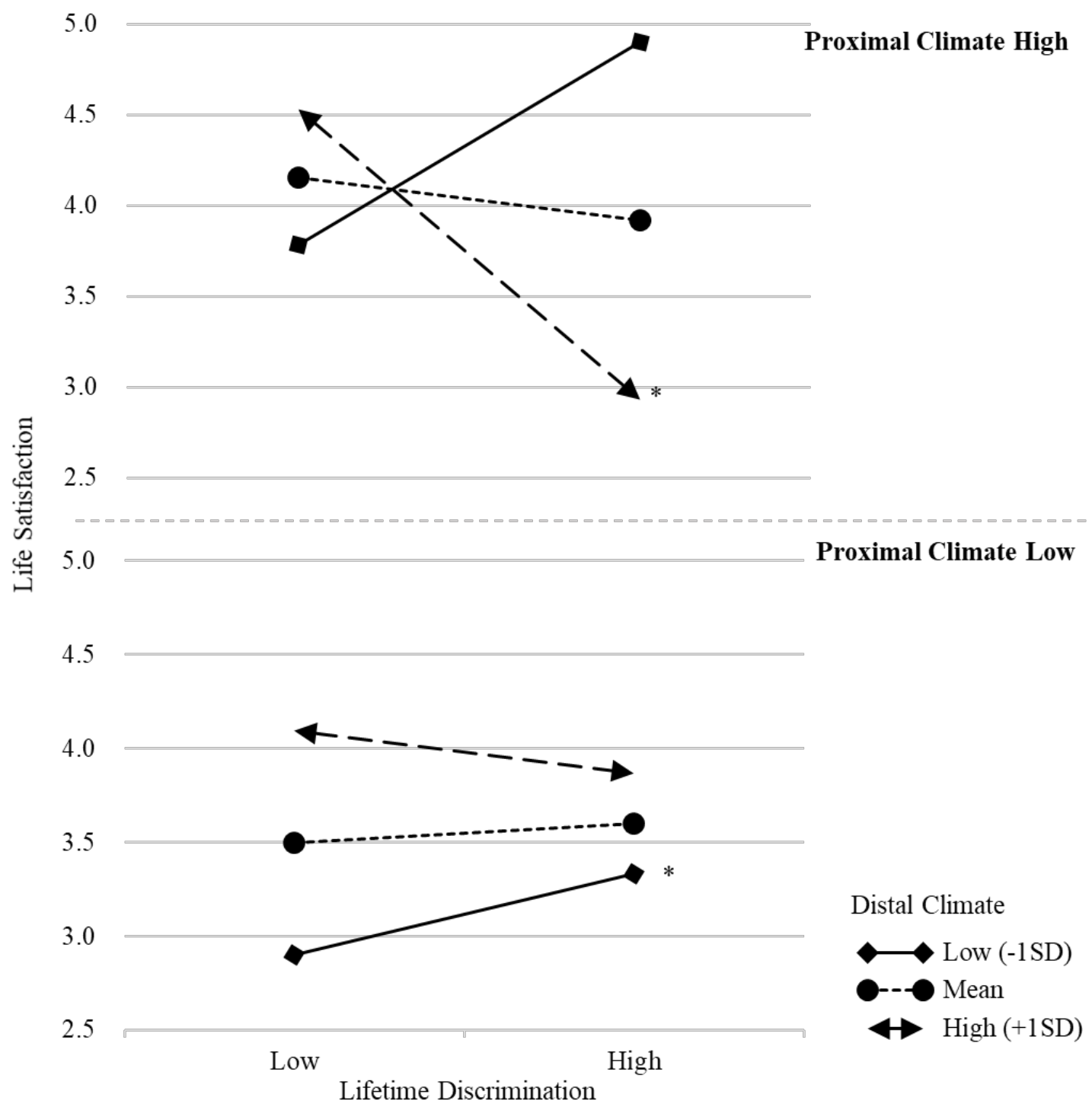

*Indicates significant simple slopes $(p<.05)$

\section{Importance of Identity and Diversity Climate}

Results of a series of independent sample t-tests between concordant and discordant groups for the three selected groups revealed significant differences for two of the three groups. 
Table 7 contains the means and standard deviations on the diversity climate subscales by concordance. Among the racial minority group, there was no mean differences on distal climate or proximal climate between the concordant and discordant groups, $t(195)=1.29, p=.20$, and $t(195)=-.84, p=.41$, respectively. Among sexual minorities, however, a significant difference emerged between concordant and discordant groups for distal climate, $t(217)=4.05, p=.001$, and proximal climate, $t(217)=3.05, p=.003$. Participants in the concordant group reported lower climate scores than those in the discordant group, suggesting that ascribing importance to a marginalized identity is associated with a more negative perception of diversity climate for that identity. For sexual and gender minorities, a similar pattern was observed whereby those in the concordant group reported lower distal and proximal climate scores than those in the discordant group, $t(115)=2.72, p=.007$, and $t(115)=1.91, p=.05$. G-power post-hoc power calculations for a small to medium effect size indicate that these exploratory analyses were underpowered, with power ranging from .32 to .61 . This is not surprising giving some of the small sub-samples involved in parsing the sample this way, but these are nevertheless informative.

In summary, the results of study 4 provided strong psychometric evidence that the DCS was valid and reliable when used in a community sample with members of diverse marginalized groups. This was true of the whole sample, broadly speaking, but also when examining the structure of the scale by the different marginalized subgroups within the sample. We also demonstrated that the different marginalized identities represented by these subgroups mattered in terms of the perception of both distal and proximal climates, with significant differences in climate perceptions across the groups. Importantly, individuals with multiple intersecting marginalized identities tended to perceive more negative climates, especially those identifying as sexual and gender minorities. Even more nuanced, within these marginalized groups, those who 
also ascribed importance to an identity they endorsed (relative to those who did not) tended to see the diversity climate as more negative. Thus, it appears that not ascribing importance to an identity they hold might allow individuals to either not perceive some of the negative aspects of their climate or not care about them or both.

Table 7

Study 4 mean differences in diversity climate by concordance between minority statuses and importance.

\begin{tabular}{|c|c|c|c|c|c|c|c|}
\hline \multirow{2}{*}{$\begin{array}{l}\text { Diversity } \\
\text { Climate } \\
\text { Subscales }\end{array}$} & \multirow[t]{2}{*}{ Concordance $^{1}$} & \multicolumn{2}{|c|}{ Racial Minority } & \multicolumn{2}{|c|}{ Sexual Minority } & \multicolumn{2}{|c|}{$\begin{array}{c}\text { Sexual and Gender } \\
\text { Minority }\end{array}$} \\
\hline & & $N$ & Mean (SD) & $N$ & Mean $(S D)$ & $N$ & $\operatorname{Mean}(S D)$ \\
\hline \multirow{2}{*}{$\begin{array}{c}\text { Distal } \\
\text { Climate }\end{array}$} & Concordant & 138 & $2.41^{\mathrm{a}}(1.00)$ & 170 & $2.01^{\mathrm{c}}(0.92)$ & 98 & $1.68^{\mathrm{h}}(0.70)$ \\
\hline & Discordant & 59 & $2.62^{\mathrm{a}}(1.11)$ & 49 & $2.66^{\mathrm{d}}(1.20)$ & 19 & $2.20^{\mathrm{i}}(1.09)$ \\
\hline \multirow{2}{*}{$\begin{array}{l}\text { Proximal } \\
\text { Climate }\end{array}$} & Concordant & 138 & $3.26^{\mathrm{b}}(1.06)$ & 170 & $2.74^{\mathrm{e}}(1.15)$ & 98 & $2.29^{j}(0.98)$ \\
\hline & Discordant & 59 & $3.12^{b}(1.13)$ & 49 & $3.30^{\mathrm{f}}(1.10)$ & 19 & $2.79^{\mathrm{k}}(1.30)$ \\
\hline
\end{tabular}

Note. ${ }^{1}$ Concordant participants included participants who endorsed the minority status/es and indicated and also indicated that the same minority status/es was/were important to their identity. Discordant participants included participants who endorsed the minority status/es and indicated that the same minority status/es was/were not important to their identity. Means that do not share a superscript within a column within each diversity climate subscale and minoritized group are significantly different from one another at $p<.05$.

Finally, we were able to show that both of the climate scales played an important role in predicting outcomes such as mental health and wellbeing, even after accounting for experiences of lifetime discrimination. Interestingly, in each case we found a three-way interaction between proximal and distal climate and discrimination, suggesting that the climate subscales contribute important information to understanding the impact of discrimination on individual psychological functioning. 


\section{General Discussion}

We constructed a measure that addresses limitations in prior literature including the capacity to assess diversity climate in a more nuanced and broad manner. Across four studies we demonstrated robust evidence for the reliability and validity of the DCS as a scale to assess different aspects of diversity climate across multiple marginalized groups and those with intersecting marginalized identities. The structure of the scale was stable across all four samples and evidenced similar psychometric properties across individuals who self-identified as being members of racial/ethnic, sexual, and/or gender minority groups. Two subscales of the DCS emerged across each of our samples, representing perceptions of distal climate (the extent to which one's social group enjoys social status, power, or respect relative to the majority) and proximal climate (experiences in the immediate environments that contribute to feelings of inclusion or exclusion). Both subscales demonstrated good convergent validity with existing measures tapping related constructs and discriminant validity with measures that are theoretically distinct. Lastly, the DCS subscales were related to important mental health and wellbeing outcomes, above and beyond measures of discrimination, pointing to the unique value of the DCS in considering health and wellbeing outcomes for members of marginalized groups, consistent with the minority stress model (Meyers, 2003) and prior research examining proximal and distal aspects of oppression (Author \& Author, 2011; Author et al., 2012).

\section{Capturing Multiple Levels of Oppression}

The data across our studies show that we can disentangle perceptions of diversity climate into (1) societal views/overall societal treatment of members of one's group and (2) everyday experiences associated with one's local context. This was the case even when considering different marginalized groups as we did in Study 4. On the one hand, the distal climate subscale 
taps into aspects of representation, status, power, and privilege (or lack thereof) experienced by one's group relative to the dominant majority. This is akin to what others have referred to as structural racism, institutional racism, and similar terms (J. Jones, 1997; Hatzenbuehler \& Link, 2014). These may be realities associated with one's marginalized status that one is aware of, but that one may not necessarily experience locally on a day-to-day basis. This also parallels the distal oppression discussed by Author and Author (2011) in their outline of multiple levels of oppression.

The proximal climate subscale, on the other hand, captures the local environment and the kinds of treatment and messages communicated to its marginalized members. Thus, this subscale is akin to the construct of interpersonal racism or discrimination (C. Jones, 2000), although it is broader in its conceptualization in terms of how it is that individuals perceive messages of being unwanted or unwelcomed. The proximal climate scale contains items that suggests that negative messages may come from direct and explicit experiences of bias (e.g., racism, sexism, etc.) in interpersonal interaction, but may also consist of more subtle slights that are often unrecognized by dominant group members (e.g., one's words/actions being quickly dismissed). We believe this subscale most closely represents the proximal level of oppression discussed by Author and Author (2011).

Both subscales interacted with experiences of discrimination to predict key outcomes suggesting that they are not providing redundant information. In fact, we see one of the main contributions of the DCS as adding greater nuance to assessments of how marginalized and oppressed groups evaluate the multiple contexts in which they exist, including local environments as well as the broader societal context. Our previous work has demonstrated that these multiple levels of oppressive contexts may be particularly important to consider in 
determining how certain behaviors (e.g., emotion regulation strategies) or experiences (e.g., previous racial climates) can impact mental health outcomes (Author \& Author, 2011; Author et al., 2012; Author et al. 2016). Thus, we see the DCS as capturing a more complex, but accurate picture of how one's diversity climate can contribute to patterns of health disparities or simply understanding the wellbeing of marginalized group members.

\section{Improving Diversity Climate Measurement}

In addition to the unpacking of diversity climate, we see several other advantages to the DCS. First, the DCS is relatively short and simple to administer at twelve items in length. Individual subscales are half that length, though we feel it is conceptually important to measure both subscales in conjunction with one another (along with the scale instructions) given the evidence that they provide different pieces of information that may, in combination with one another, predict outcomes of interest. When paired with the richness that the subscales provide, the simplicity of the DCS offers a valuable measurement tool for researchers interested in quantifying the impacts of diversity climate.

Second, the DCS offers significant versatility in that it can be used to capture diversity climate from individuals representing a range of marginalized identities. The current instructions provide up to six major domains of social identities (race, gender, sexual orientation, religion, nationality, SES) for individuals to focus on when they complete the scale and this is based on their own indication of which of these identities are most important to them. Other existing scales may focus on racial climate (Reid \& Radhakrishnan, 2003) or LGB climate (Oswald et al., 2010), but the DCS allows researchers to measure climate for different groups with the same measure. Of course, there are aspects of climate that are unique for members of certain marginalized groups (e.g., concerns about being with partners in public for LGB individuals; 
expectations that Christian holidays are celebrated for religious minorities) but capturing the common core of diversity climate across multiple groups illuminates the interconnectedness of oppression and goes beyond individual social groups to create broadly inclusive communities.

Our data also demonstrate the richness in allowing participants to indicate how important they believe multiple marginalized statuses to be for their identity. The selection of an identity as important to one's sense of self, beyond simply claiming an identity on a demographic questionnaire, directly related to seeing the diversity climate for those identities as more negative. This might simply reflect a realistic assessment by those who are attuned to what it means to be a member of a marginalized group (because they ascribed importance to it), whereas not ascribing importance to an identity one claims could provide psychological distance from aspects of one's environment that might otherwise suggest a worse climate.

The ability of participants to indicate on the DCS which identities are important to them also begins to provide a mechanism for examining how intersecting identities can change aspects of one's perceived climate relative to those who primarily identify with one marginalized identity. Although psychology is beginning to recognize the importance of intersectional approaches from a conceptual standpoint, methodology is lagging and there are still many more questions than answers when it comes to how to incorporate intersectionality into psychological science (Shields, 2008; Torres et al., 2018). Nevertheless, the DCS offers a useful approach for considering how multiple identities might shape diversity climate perceptions and whether differences in such translate to differences in wellbeing, mental health, or other important outcomes.

\section{Limitations and Future Directions}


There are some noteworthy limitations of the present work that merit discussion. First, despite the broader diversity in the last sample (in terms of representation of different marginalized groups), our other samples were heavily focused on college-aged ethnic and racial minority participants. We attempted to broaden the representativeness of the ethnic minority participants by also gathering a nation-wide sample of post-secondary students as well as a community sample of diverse marginalized groups. In future work, it will be important to examine how the DCS performs with samples with a much larger number of participants from each of the marginalized identities of interest. In the current study, looking at specific identity intersections led to a significant drop-off in the size of certain subgroups which made some of the desired analyses untenable.

Another weakness of the present study was our inability to distinguish the impacts of the DCS from the impacts of measuring belongingness. As discussed previously, we believe there is overlap between the concept of diversity climate and belongingness, but also see important differences. We believe this is parallel to the relationship between our diversity climate subscales and the measures of discrimination included in our studies. In these instances, we saw some evidence that these constructs are moderately related, but far from redundant. Reflective of this fact, the climate scales predicted variance in mental health and wellbeing outcomes above and beyond measures of discrimination and discrimination interacted with both climate scales in predicting these outcomes. Given that diversity climate taps into aspects of inclusiveness and representation, belongingness is bound to be a relevant concept to take into consideration. Including measures of belongingness in future work will help disentangle the unique contributions that diversity climate provides beyond just assessing belongingness. 
A final limitation is that the individual items of the DCS are all negatively worded. We initially included some items that were positively worded, but these items loaded on a third scale that was unviable as a stand-alone factor. These two items (see factor 3, Table 1) captured representation of members of one's group in one's local community and may have clustered together for that reason. However, measuring representation of particular marginalized groups may be more efficiently done with a single item or by obtaining demographic information for certain contexts (schools, businesses, neighborhoods, etc.), although this is dependent on this information being available. As mentioned in study 1 , these two items may have also loaded on the same factor because they were the only ones that were positively worded. Of course, the negatively worded items in the scale inherently represent an inverse of a positive climate statement, providing a space to capture those experiences as well. Unfortunately, the more common experience for members many marginalized groups is a more negative diversity climate (as evidenced by our own data) and, in that sense, the current wording of the DCS may be more consistent with the lived experience of participants of interest.

\section{Conclusion}

Our society is becoming increasingly aware of the multiple and insidious ways that injustice, bias, and unequal treatment of marginalized groups are reflected, propagated, and instantiated within individuals and the social structures they occupy and create. For members of marginalized groups, the totality of these realities can be perceived or intuited via implicit and explicit messages in the environment that result in an overall sense of diversity climate. Precise measurement of this climate is critical for understanding the lived experience of marginalized members of our society, as well as for motivating structural and environmental changes to help improve the diversity climate. These studies are an important first step toward providing the 
careful assessment of diversity climate that is needed for the improvement of the intergroup processes that contribute to the development of a positive climate for all. 


\section{References}

Alegria, M., Vallas, M., \& Pumariega, A. J. (2010). Racial and Ethnic Disparities in Pediatric Mental Health. Child and Adolescent Psychiatric Clinics of North America, 19(4), 759774. https://doi.org/10.1016/j.chc.2010.07.001

American Psychological Association. (2020, May 29). 'We are living in a racism pandemic,' says APA President [Press release]. http://www.apa.org/news/press/releases/2020/05/racismpandemic

Arrindell, W. A., \& Van der Ende, J. (1985). An empirical test of the utility of the observationsto-variables ratio in factor and components analysis. Applied Psychological Measurement, 9(2), 165-178. doi:http://dx.doi.org/10.1177/014662168500900205

Authors. (2011).

Authors. (2012).

Authors. (2016).

Bandalos D. L., Finney S. J. (2010). Factor analysis. Exploratory and confirmatory. In Hancock G. R., Mueller R. O. (Eds.), The reviewer's guide to quantitative methods in the social science (pp. 93-114). New York: Routledge.

Barnette, J. J. (2000). Effects of stem and Likert response option reversals on survey internal consistency: If you feel the need, there is a better alternative to using those negatively worded stems. Educational and psychological measurement, 60(3), 361-370. https://doi.org/10.1177\%2F00131640021970592

Baumeister, R. F., \& Leary, M. R. (1995). The need to belong: Desire for interpersonal attachments as a fundamental human motivation. Psychological Bulletin, 117(3), 497529. https://doi.org/10.1037/0033-2909.117.3.497 
Begeny, C. T., \& Huo, Y. J. (2017). When identity hurts: How positive intragroup experiences can yield negative mental health implications for ethnic and sexual minorities. European Journal of Social Psychology, 47(7), 803-817. https://doi.org/10.1002/ejsp.2292

Bell, C. N., Sacks, T. K., Tobin, C. S. T., \& Thorpe Jr, R. J. (2020). Racial non-equivalence of socioeconomic status and self-rated health among African Americans and Whites. SSMPopulation Health, 10, 1-9. https://doi.org/10.1016/j.ssmph.2020.100561

Bentler, P. M. (1990). Comparative fit indexes in structural models. Psychological Bulletin, 107(2), 238-246. https://doi.org/10.1037/0033-2909.107.2.238

Bentler, P. M., \& Chou, C.-P. (1987). Practical Issues in Structural Modeling. Sociological Methods \& Research, 16(1), 78-117. https://doi.org/10.1177/0049124187016001004

Birkett, M., Espelage, D. L., \& Koenig, B. (2009). LGB and Questioning Students in Schools: The Moderating Effects of Homophobic Bullying and School Climate on Negative Outcomes. Journal of Youth and Adolescence, 38(7), 989-1000. https://doi.org/10.1007/s10964-008-9389-1

Bowleg, L. (2008). When Black + Lesbian + Woman $\neq$ Black Lesbian Woman: The Methodological Challenges of Qualitative and Quantitative Intersectionality Research. Sex Roles, 59(5), 312-325. https://doi.org/10.1007/s11199-008-9400-z

Brondolo, E., Rieppi, R., Kelly, K. P., \& Gerin, W. (2003). Perceived racism and blood pressure: A review of the literature and conceptual and methodological critique. Annals of Behavioral Medicine, 25(1), 55-65. https://doi.org/10.1207/S15324796ABM2501_08

Browne, M. W. \& Cudeck, R. (1993). Alternative ways of assessing model fit. In K. A. Bollen \& J. S. Long (Eds.), Testing structural equation models. Sage. 
Byrd, C. M., \& Chavous, T. (2011). Racial Identity, School Racial Climate, and School Intrinsic Motivation Among African American Youth: The Importance of Person-Context Congruence. Journal of Research on Adolescence, 21(4), 849-860. https://doi.org/10.1111/j.1532-7795.2011.00743.x

Cabrera, A. F., \& Nora, A. (1994). College Students’ Perceptions of Prejudice and Discrimination and Their Feelings of Alienation: A Construct Validation Approach. Review of Education, Pedagogy, and Cultural Studies, 16(3-4), 387-409. https://doi.org/10.1080/1071441940160310

Cabrera, A. F., Nora, A., Terenzini, P. T., Pascarella, E., \& Hagedorn, L. S. (1999). Campus Racial Climate and the Adjustment of Students to College. The Journal of Higher Education, 70(2), 134-160. https://doi.org/10.1080/00221546.1999.11780759

Center for Disease Control and Prevention. (2013). CDC Health Disparities and Inequalities Report-United States, 2013. MMWR. Morbidity and Mortality Weekly Report, 62 (3), $1-187$

Chavous, T. M. (2005). An Intergroup Contact-Theory Framework for Evaluating Racial Climate on Predominantly White College Campuses. American Journal of Community Psychology, 36(3-4), 239-257. https://doi.org/10.1007/s10464-005-8623-1

Chen, E., Martin, A. D., \& Matthews, K. A. (2006). Understanding Health Disparities: The Role of Race and Socioeconomic Status in Children's Health. American Journal of Public Health, 96(4), 702-708. https://doi.org/10.2105/AJPH.2004.048124

Clark, R., Anderson, N. B., Clark, V. R., \& Williams, D. R. (1999). Racism as a stressor for African Americans: A biopsychosocial model. American Psychologist, 54(10), 805-816. https://doi.org/10.1037/0003-066X.54.10.805 
Comrey, A. L., \& Lee, H. B. (1992). A First Course in Factor Analysis. Hillsdale, NJ: Lawrence Eribaum Associates.

Cose, E. (1995). The Rage of a Privileged Class. New York: Harper Perennial.

Crenshaw, K. (1989). Demarginalizing the Intersection of Race and Sex: A Black Feminist Critique of Antidiscrimination Doctrine, Feminist Theory and Antiracist Politics. University of Chicago Legal Forum, 1989(1). https://chicagounbound.uchicago.edu/uclf/vol1989/iss1/8

Cronbach, L. (1950). Further evidence on response sets and test design. Educational and Psychological Measurement, 10, 3-31.

Davis, M., Dias-Bowie, Y., Greenberg, K., Klukken, G., Pollio, H. R., Thomas, S. P., \& Thompson, C. L. (2004). "A Fly in the Buttermilk": Descriptions of University Life by Successful Black Undergraduate Students at a Predominately White Southeastern University. The Journal of Higher Education, 75(4), 420-445. https://doi.org/10.1080/00221546.2004.11772266

Diener, E., Emmons, R. A., Larsen, R. J., \& Griffin, S. (1985). The Satisfaction with Life Scale. Journal of Personality Assessment, 49(1), 71-75. https://doi.org/10.1207/s15327752jpa4901_13

DiStefano, C., \& Motl, R. W. (2006). Further investigating method effects associated with negatively worded items on self-report surveys. Structural Equation Modeling, 13(3), 440-464. https://doi.org/10.1207/s15328007sem1303_6

Dixon-Fyle, S., Dolan, K., Hunt, V., \& Prince, S. (2020). Diversity wins: How inclusion matters. McKinsey \& Company. https://www.mckinsey.com/featured-insights/diversity-andinclusion/diversity-wins-how-inclusion-matters\#. 
Dovidio, J. F. (2001). On the nature of contemporary prejudice: The third wave. Journal of Social Issues, 57(4), 829-849. https://doi.org/10.1111/0022-4537.00244

Downey, S. N., Werff, L. van der, Thomas, K. M., \& Plaut, V. C. (2015). The role of diversity practices and inclusion in promoting trust and employee engagement. Journal of Applied Social Psychology, 45(1), 35-44. https://doi.org/10.1111/jasp.12273

Erdfelder, E., Faul, F., \& Buchner, A. (2005). GPOWER: A general power analysis program. Behavior Research Methods, Instruments, \& Computers, 28, 1-11.

French, S. E., Seidman, E., Allen, L., \& Aber, J. L. (2000). Racial/Ethnic Identity, Congruence with the Social Context, and the Transition to High School. Journal of Adolescent Research, 15(5), 587-602. https://doi.org/10.1177/0743558400155004

Goodenow, C. (1993). Classroom Belonging among Early Adolescent Students: Relationships to Motivation and Achievement. The Journal of Early Adolescence, 13(1), 21-43. https://doi.org/10.1177/0272431693013001002

Graham, S. (2011). School Racial/Ethnic Diversity and Disparities in Mental Health and Academic Outcomes. In G. Carlo, L. J. Crockett, \& M. A. Carranza (Eds.), Health Disparities in Youth and Families: Research and Applications (pp. 73-96). Springer. https://doi.org/10.1007/978-1-4419-7092-3_4

Gross, J. J., \& John, O. P. (2003). Individual differences in two emotion regulation processes: Implications for affect, relationships, and well-being. Journal of Personality and Social Psychology, 85(2), 348-362. https://doi.org/10.1037/0022-3514.85.2.348

Guion, R. M. (1973). A note on organizational climate. Organizational Behavior and Human Performance, 9(1), 120-125. https://doi.org/10.1016/0030-5073(73)90041-X 
Hatzenbuehler, M. L. (2011). The Social Environment and Suicide Attempts in Lesbian, Gay, and Bisexual Youth. Pediatrics, 127(5), 896-903. https://doi.org/10.1542/peds.2010$\underline{3020}$

Hatzenbuehler, M. L., \& Link, B. G. (2014). Introduction to the special issue on structural stigma and health. Social Science \& Medicine, 103, 1-6. https://doi.org/10.1016/j.socscimed.2013.12.017

Andrew F. Hayes (2013). Introduction to Mediation, Moderation, and Conditional Process Analysis: A Regression-Based Approach. New York, NY: The Guilford Press

Hoyle, R. H., \& Crawford, A. M. (1994). Use of Individual-Level Data to Investigate Group Phenomena Issues and Strategies. Small Group Research, 25(4), 464-485. https://doi.org/10.1177/1046496494254003

Hu, L., \& Bentler, P. M. (1999). Cutoff criteria for fit indexes in covariance structure analysis: Conventional criteria versus new alternatives. Structural Equation Modeling: A Multidisciplinary Journal, 6(1), 1-55. https://doi.org/10.1080/10705519909540118

Hurtado, S. (1992). The Campus Racial Climate. The Journal of Higher Education, 63(5), 539569. https://doi.org/10.1080/00221546.1992.11778388

Hurtado, S., Clayton-Pedersen, A. R., Allen, W. R., \& Milem, J. F. (1998). Enhancing Campus Climates for Racial/Ethnic Diversity: Educational Policy and Practice. The Review of Higher Education, 21(3), 279-302. https://doi.org/10.1353/rhe.1998.0003

Hurtado, S., Griffin, K. A., Arellano, L., \& Cuellar, M. (2008). Assessing the value of climate assessments: Progress and future directions. Journal of Diversity in Higher Education, 1(4), 204-221. https://doi.org/10.1037/a0014009

IBM Corp. (2020). IBM SPSS Statistics for Windows, Version 27.0. Armonk, NY: IBM Corp. 
James, R. (1998). The perceived effects of social alienation on Black college students enrolled at a Caucasian southern university. College Student Journal, 32, 228-239.

Johnson, D. R., Soldner, M., Leonard, J. B., Alvarez, P., Inkelas, K. K., Rowan-Kenyon, H. T., \& Longerbeam, S. D. (2007). Examining Sense of Belonging Among First-Year Undergraduates From Different Racial/Ethnic Groups. Journal of College Student Development, 48(5), 525-542. https://doi.org/10.1353/csd.2007.0054

Jones, C. P. (2000). Levels of racism: A theoretic framework and a gardener's tale. American Journal of Public Health, 90(8), 1212-1215. https://doi.org/10.2105/AJPH.90.8.1212

Jones, C. P. (2002). Confronting Institutionalized Racism. Phylon (1960-), 50(1/2), 7-22. https://doi.org/10.2307/4149999

Jones, J. M. (1997). Prejudice and racism (2 ${ }^{\text {nd }}$ ed.). New York: McGraw-Hill.

Kosciw, J. G., Greytak, E. A., \& Diaz, E. M. (2009). Who, what, where, when, and why: demographic and ecological factors contributing to hostile school climate for lesbian, gay, bisexual, and transgender youth. Journal of youth and adolescence, 38(7), 976-988. https://doi.org/10.1007/s10964-009-9412-1

Kossek, E. E., \& Zonia, S. C. (1993). Assessing diversity climate: A field study of reactions to employer efforts to promote diversity. Journal of Organizational Behavior, 14(1), 61-81. https://doi.org/10.1002/job.4030140107

Kyriazos, T. A. (2018). Applied Psychometrics: Sample Size and Sample Power Considerations in Factor Analysis (EFA, CFA) and SEM in General. Psychology, 9, 2207-2230. https://doi.org/10.4236/psych.2018.98126

Lick, D. J., Tornello, S. L., Riskind, R. G., Schmidt, K. M., \& Patterson, C. J. (2012). Social Climate for Sexual Minorities Predicts Well-Being Among Heterosexual Offspring of Lesbian and Gay Parents. Sexuality Research and Social Policy, 9(2), 99-112. 
https://doi.org/10.1007/s13178-012-0081-6

Likert, R. (1932). A technique for the measurement of attitudes. Archives of Psychology, 140, 455

Locks, A. M., Hurtado, S., Bowman, N. A., \& Oseguera, L. (2008). Extending Notions of Campus Climate and Diversity to Students' Transition to College. The Review of Higher Education, 31(3), 257-285. https://doi.org/10.1353/rhe.2008.0011

Lukachko, A., Hatzenbuehler, M. L., \& Keyes, K. M. (2014). Structural racism and myocardial infarction in the United States. Social Science \& Medicine, 103, 42-50. https://doi.org/10.1016/j.socscimed.2013.07.021

Maurizi, L. K., Ceballo, R., Epstein-Ngo, Q., \& Cortina, K. S. (2013). Does neighborhood belonging matter? Examining school and neighborhood belonging as protective factors for Latino adolescents. American Journal of Orthopsychiatry, 83(2-3), 323334. https://doi.org/10.1111/ajop.12017

McKay, P. F., Avery, D. R., \& Morris, M. A. (2008). Mean Racial-Ethnic Differences in Employee Sales Performance: The Moderating Role of Diversity Climate. Personnel Psychology, 61(2), 349-374. https://doi.org/10.1111/j.1744-6570.2008.00116.x

McKay, P. F., Avery, D. R., Tonidandel, S., Morris, M. A., Hernandez, M., \& Hebl, M. R. (2007). Racial Differences in Employee Retention: Are Diversity Climate Perceptions the Key? Personnel Psychology, 60(1), 35-62. https://doi.org/10.1111/j.1744$\underline{6570.2007 .00064 . x}$

Meyer, I. H. (2003). Prejudice, social stress, and mental health in lesbian, gay, and bisexual populations: Conceptual issues and research evidence. Psychological Bulletin, 129(5), 674-697. https://doi.org/10.1037/0033-2909.129.5.674 
Mor Barak, M. E., Cherin, D. A., \& Berkman, S. (1998). Organizational and Personal Dimensions in Diversity Climate: Ethnic and Gender Differences in Employee Perceptions. The Journal of Applied Behavioral Science, 34(1), 82-104. https://doi.org/10.1177/0021886398341006

Mor Barak, M. E., Luria, G., \& Brimhall, K. C. (2021). What Leaders Say versus What They Do: Inclusive Leadership, Policy-Practice Decoupling, and the Anomaly of Climate for Inclusion. Group \& Organization Management, 10596011211005916. https://doi.org/10.1177/10596011211005916

Mounts, N. S. (2004). Contributions of Parenting and Campus Climate to Freshmen Adjustment in a Multiethnic Sample. Journal of Adolescent Research, 19(4), 468-491. https://doi.org/10.1177/0743558403258862

Muthén, L. K., \& Muthén, B. O. (2017). Mplus User's Guide. Eighth Edition. Los Angeles, CA: Muthén \& Muthén.

National Center for Chronic Disease Prevention and Health Promotion (2004), Physical Activity and Good Nutrition: Essential Elements to Prevent Chronic Diseases and Obesity. Atlanta, GA: Centers for Disease Control and Prevention. http://www.cdc.gov/nccdphp/aag/aag_dnpa.htm.

Neblett Jr., E. W. (2019). Racism and health: Challenges and future directions in behavioral and psychological research. Cultural Diversity and Ethnic Minority Psychology, 25(1), 12 20. https://doi.org/10.1037/cdp0000253

Nettles, M. T., \& Perna, L. W. (1997). The African American Education Data Book. Volume I: Higher and Adult Education. Executive Summary. Frederick D. https://eric.ed.gov/?id=ED406870 
Nettles, M. T., Thoeny, A. R., \& Gosman, E. J. (1986). Comparative and Predictive Analyses of Black and White Students' College Achievement and Experiences. The Journal of Higher Education, 57(3), 289-318. https://doi.org/10.1080/00221546.1986.11778772

Nunnally, J. C. (1967), Psychometric Theory (1 $1^{\text {st }}$ ed.). New York, NY: McGraw-Hill.

Oswald, R. F., Cuthbertson, C., Lazarevic, V., \& Goldberg, A. E. (2010). New Developments in the Field: Measuring Community Climate. Journal of GLBT Family Studies, 6(2), 214228. https://doi.org/10.1080/15504281003709230

Paradies, Y., Ben, J., Denson, N., Elias, A., Priest, N., Pieterse, A., Gupta, A., Kelaher, M., \& Gee, G. (2015). Racism as a Determinant of Health: A Systematic Review and MetaAnalysis. PLOS ONE, 10(9), e0138511. https://doi.org/10.1371/journal.pone.0138511

Pargament, K. I., Silverman, W., Johnson, S., Echemendia, R., \& Snyder, S. (1983). The psychosocial climate of religious congregations. American Journal of Community Psychology, 11(4), 351-381. https://doi.org/10.1007/BF00894054

Pearson, A. R., Dovidio, J. F., \& Gaertner, S. L. (2009). The Nature of Contemporary Prejudice: Insights from Aversive Racism. Social and Personality Psychology Compass, 3(3), 314338. https://doi.org/10.1111/j.1751-9004.2009.00183.x

Petersen, A. (2019). Exploring Black Student Success with a Mixed Methods Investigation of Retention in the Second Year of College. http://hdl.handle.net/10211.3/209380

Phinney, J. S. (1996). Understanding Ethnic Diversity: The Role of Ethnic Identity. American Behavioral Scientist, 40(2), 143-152. https://doi.org/10.1177/0002764296040002005

Pittman, L. D., \& Richmond, A. (2007). Academic and Psychological Functioning in Late Adolescence: The Importance of School Belonging. The Journal of Experimental Education, 75(4), 270-290. https://doi.org/10.3200/JEXE.75.4.270-292 
Plaut, V. C., Cheryan, S., \& Stevens, F. G. (2015). New frontiers in diversity research:

Conceptions of diversity and their theoretical and practical implications. In $A P A$ handbook of personality and social psychology, Volume 1: Attitudes and social cognition (pp. 593-619). American Psychological Association. https://doi.org/10.1037/14341-019

Radloff, L. S. (1977). The CES-D Scale: A Self-Report Depression Scale for Research in the General Population. Applied Psychological Measurement, 1(3), 385-401. https://doi.org/10.1177/014662167700100306

Reid, L. D., \& Radhakrishnan, P. (2003). Race matters: The relation between race and general campus climate. Cultural Diversity and Ethnic Minority Psychology, 9(3), 263-275. https://doi.org/10.1037/1099-9809.9.3.263

Roeser, R. W., Midgley, C., \& Urdan, T. C. (1996). Perceptions of the school psychological environment and early adolescents' psychological and behavioral functioning in school: The mediating role of goals and belonging. Journal of Educational Psychology, 88(3), 408-422. https://doi.org/10.1037/0022-0663.88.3.408

Salter, P. S., Adams, G., \& Perez, M. J. (2018). Racism in the Structure of Everyday Worlds: A Cultural-Psychological Perspective. Current Directions in Psychological Science, 27(3), 150-155. https://doi.org/10.1177/0963721417724239

Salter, P., \& Adams, G. (2013). Toward a Critical Race Psychology. Social and Personality Psychology Compass, 7(11), 781-793. https://doi.org/10.1111/spc3.12068

Schiffrin, H. H., Liss, M., Miles-McLean, H., Geary, K. A., Erchull, M. J., \& Tashner, T. (2014). Helping or Hovering? The Effects of Helicopter Parenting on College Students' WellBeing. Journal of Child and Family Studies, 23(3), 548-557. https://doi.org/10.1007/s10826-013-9716-3 
Schweizer, K., \& Rauch, W. (2008). An investigation of the structure of the social optimism scale in considering the dimensionality problem. Journal of Individual Differences, 29, 223-230. https://doi.org/10.1027/1614-0001.29.4.223

Sellers, R. M., Rowley, S. A. J., Chavous, T. M., Shelton, J. N., \& Smith, M. A. (1997). Multidimensional Inventory of Black Identity: A preliminary investigation of reliability and construct validity. Journal of Personality and Social Psychology, 73(4), 805-815. https://doi.org/10.1037/0022-3514.73.4.805

Sellers, R. M., Smith, M. A., Shelton, J. N., Rowley, S. A. J., \& Chavous, T. M. (1998). Multidimensional Model of Racial Identity: A Reconceptualization of African American Racial Identity. Personality and Social Psychology Review, 2(1), 18-39. https://doi.org/10.1207/s15327957pspr0201_2

Shields, S. A. (2008). Gender: An Intersectionality Perspective. Sex Roles, 59(5), 301-311. https://doi.org/10.1007/s11199-008-9501-8

Sliter, K. A., \& Zickar, M. J. (2014). An IRT examination of the psychometric functioning of negatively worded personality items. Educational and Psychological Measurement, 74(2), 214-226. https://doi.org/10.1177\%2F0013164413504584

Solórzano, D. G., \& Bernal, D. D. (2001). Examining Transformational Resistance Through a Critical Race and Latcrit Theory Framework: Chicana and Chicano Students in an Urban Context. Urban Education, 36(3), 308-342. https://doi.org/10.1177/0042085901363002

Solórzano, D., Ceja, M., \& Yosso, T. (2000). Critical Race Theory, Racial Microaggressions, and Campus Racial Climate: The Experiences of African American College Students. The Journal of Negro Education, 69(1/2), 60-73. 
Spector, P., Van Katwyk, P., Brannick, M., \& Chen, P. (1997). When two factors don't reflect two constructs: How item characteristics can produce artifactual factors. Journal of Management, 23, 659-677. https://doi.org/10.1177\%2F014920639702300503

Steele, C. M. (1997). A threat in the air: How stereotypes shape intellectual identity and performance. American Psychologist, 52(6), 613-629. https://doi.org/10.1037/0003066X.52.6.613

Steele, C. M. (1999, August 1). Thin Ice: Stereotype Threat and Black College Students. The Atlantic. https://www.theatlantic.com/magazine/archive/1999/08/thin-ice-stereotypethreat-and-black-college-students/304663/

Steele, C. M. (2004). A threat in the air: How stereotypes shape intellectual identity and performance. In J. Banks \& C. Banks (Eds.), Handbook of research on multicultural education (2nd edition) (pp. 682-699). San Francisco, CA: Jossey-Bass.

Steele, C. M., \& Aronson, J. (1995). Stereotype threat and the intellectual test performance of African Americans. Journal of Personality and Social Psychology, 69(5), 797-811. https://doi.org/10.1037/0022-3514.69.5.797

Steiger, J. H., \& Lind, J. C. (1980, May). Statistically based tests for the number of factors. Paper presented at the annual spring meeting of the Psychometric Society, Iowa City, IA.

Stevens, P. A. J., Clycq, N., Timmerman, C., \& Houtte, M. V. (2010). Researching race/ethnicity and educational inequality in the Netherlands: A critical review of the research literature between 1980 and 2008. British Educational Research Journal, 37(1), 5-43. https://doi.org/10.1080/01411920903342053

Tao, S., Dong, Q., Pratt, M. W., Hunsberger, B., \& Pancer, S. M. (2000). Social Support: Relations to Coping and Adjustment During the Transition to University in the People's 
Republic of China. Journal of Adolescent Research, 15(1), 123-144. https://doi.org/10.1177/0743558400151007

Thomas, K. M., \& Plaut, V. C. (2008). The many faces of diversity resistance in the workplace. In Diversity resistance in organizations (pp. 1-22). Taylor \& Francis Group/Lawrence Erlbaum Associates.

Torres, L., Mata-Greve, F., Bird, C., \& Herrera Hernandez, E. (2018). Intersectionality research within Latinx mental health: Conceptual and methodological considerations. Journal of Latina/o Psychology, 6(4), 304. https://doi.org/10.1037/lat0000122

Tucker, L. R., \& Lewis, C. (1973). A reliability coefficient for maximum likelihood factor analysis. Psychometrika, 38(1), 1-10. https://doi.org/10.1007/BF02291170

Unzueta, M. M., \& Binning, K. R. (2012). Diversity Is in the Eye of the Beholder: How Concern for the In-Group Affects Perceptions of Racial Diversity. Personality and Social Psychology Bulletin, 38(1), 26-38. https://doi.org/10.1177/0146167211418528

Walton, G. M., \& Cohen, G. L. (2007). A question of belonging: Race, social fit, and achievement. Journal of Personality and Social Psychology, 92(1), 82-96. https://doi.org/10.1037/0022-3514.92.1.82

Weems, G. H., \& Onwuegbuzie, A. J. (2001). The impact of midpoint responses and reverse coding on survey data. Measurement and Evaluation in Counseling and Development, 34 , 166-176. https://doi.org/10.1080/07481756.2002.12069033

Williams, D. R. (1999). Race, Socioeconomic Status, and Health: The Added Effects of Racism and Discrimination. Annals of the New York Academy of Sciences, 896(1), 173-188. https://doi.org/10.1111/j.1749-6632.1999.tb08114.x

Williams, D. R., \& Jackson, P. B. (2005). Social Sources Of Racial Disparities In Health. Health 
Affairs, 24(2), 325-334. https://doi.org/10.1377/hlthaff.24.2.325

Williams, D. R., Lawrence, J. A., \& Davis, B. A. (2019). Racism and Health: Evidence and Needed Research. Annual Review of Public Health, 40(1), 105-125. https://doi.org/10.1146/annurev-publhealth-040218-043750

Williams, D. R., Yu, Y., Jackson, J. S., \& Anderson, N. B. (1997). Racial Differences in Physical and Mental Health: Socio-economic Status, Stress and Discrimination. Journal of Health Psychology, 2(3), 335-351. https://doi.org/10.1177/135910539700200305

Zeng, B., Wen, H., \& Zhang, J. (2020). How does the valence of wording affect features of a scale? The method effects in the Undergraduate Learning Burnout Scale. Frontiers in Psychology, 11, 2638. https://doi.org/10.3389/fpsyg.2020.585179 